Research Article

\title{
Isolation and Identification of Chemical Constituents from Zhideke Granules by Ultra-Performance Liquid Chromatography Coupled with Mass Spectrometry
}

\author{
Guangqiang Huang $\left(\mathbb{D},{ }^{1}\right.$ Jie Liang $\left(\mathbb{D},{ }^{1,2,3}\right.$ Xiaosi Chen, ${ }^{1}$ Jing Lin, ${ }^{1}$ Jinyu Wei, \\ Dongfang Huang, ${ }^{1}$ Yushan Zhou, ${ }^{1}$ Zhengyi Sun, ${ }^{4}$ and Lichun Zhao $\mathbb{\circledR}^{1,3}$ \\ ${ }^{1}$ College of Pharmacy, Guangxi University of Chinese Medicine, Nanning 530200, China \\ ${ }^{2}$ Guangxi Key Laboratory of Zhuang and Yao Ethnic Medicine, Nanning 530200, China \\ ${ }^{3}$ Guangxi Zhuang Yao Medicine Center of Engineering and Technology, Nanning 530200, China \\ ${ }^{4}$ Ruikang Hospital Affiliated to Guangxi University of Chinese Medicine, Nanning 530011, China \\ Correspondence should be addressed to Jie Liang; liangjie1101@126.com and Lichun Zhao; hyzlc@126.com
}

Received 25 August 2020; Accepted 8 December 2020; Published 29 December 2020

Academic Editor: Luca Campone

Copyright (c) 2020 Guangqiang Huang et al. This is an open access article distributed under the Creative Commons Attribution License, which permits unrestricted use, distribution, and reproduction in any medium, provided the original work is properly cited.

\begin{abstract}
Chemical constituents from Zhideke granules were rapidly isolated and identified by ultra-performance liquid chromatography (UPLC) coupled with hybrid quadrupole-orbitrap mass spectrometry (MS) in positive and negative ion modes using both full scan and two-stage threshold-triggered mass modes. The secondary fragment ion information of the target compound was selected and compared with the compound reported in databases and related literatures to further confirm the possible compounds. A total of 47 chemical constituents were identified from the ethyl acetate extract of Zhideke granules, including 21 flavonoids and glycosides, 9 organic acids, 4 volatile components, 3 nitrogen-containing compounds, and 10 other compounds according to the fragmentation patterns, relevant literature, and MS data. The result provides a new method for the analysis of chemical constituents of Zhideke granules which laid the foundation for quality control and the study of pharmacodynamic materials of Zhideke granules.
\end{abstract}

\section{Introduction}

Zhideke granules are an in-hospital preparation from Ruikang Hospital affiliated to the Guangxi University of Chinese Medicine. It contains 10 kinds of traditional Chinese medicines including Scutellaria baicalensis Georgi., Belamcanda chinensis (L.) Redouté, Mentha haplocalyx Briq., Eriobotrya japonica (Thunb.), Platycodon grandiflorus (Jacq.) A. DC., Bupleurum chinense, Nepeta cataria L., Cynanchum glaucescens (Decne.) Hand-Mazz., Nervilia fordii (Hance) Schltr., and Sauropus spatulifolius Beille. The preparation that has been used in the treatment of bronchial asthma of wind-phlegm obstructing the lung in acute attack period for many years is widely used in Guangxi Zhuang Autonomous Region of China [1]. It has the efficacy of reducing fever and removing toxins, relieving cough and resolving phlegm. Moreover, it has been proven by longterm clinical practice that Zhideke granules have an effect on flu, fever, cough, bronchial asthma, etc. [2,3]. Although it has been reported that baicalin in Scutellaria baicalensis Georgi. and tectoridin and irisflorentin in Belamcanda chinensis (L.) Redouté are used as quality control components of Zhideke granules, the material base of it is still unclear. At the same time, some literatures about baicalin $[4,5]$ and tectoridin $[6,7]$ proved that they had antiasthma effect and reduced inflammation. However, other chemical constituents and pharmacodynamic substances of Zhideke granules have not been reported.

The ultra-performance liquid chromatography coupled with hybrid quadrupole-orbitrap mass spectrometry (UPLC-Q-Orbitrap HRMS) is a new technology developed in recent years for analyzing the structure of complex 
traditional Chinese medicine (TCM) and its compound preparations [8-11], and it has the advantages of high efficiency, high speed, high sensitivity, and high resolution and specificity [12-14]. In this study, UPLC-Q-Orbitrap HRMS was used to rapidly isolate and identify unknown chemical components in Zhideke granules for the first time. We analysed the secondary fragment ion information of the target compound as well as relevant literature to further determine the possible chemical constituents in Zhideke granules, which has provided a reference for the quality control and its pharmacodynamics substances of Zhideke granules.

\section{Materials and Methods}

2.1. Chemicals and Reagents. Zhideke granules were provided by Ruikang Hospital affiliated to Guangxi University of Chinese Medicine. UPLC-grade acetonitrile was purchased from Merck (Merck, Germany). UPLC-grade ammonium acetate was obtained from Shanghai Sixin Biotechnology Co., Ltd. (Shanghai, China). Formic acid and methanol at UPLC-grade were acquired from Fisher (Fisher, USA). Analytical grade ethyl acetate was purchased from Fisher (Fisher, USA). Ultra-pure water was purified with Milli-Q synergy (Millipore, USA). Forsythoside A (no. 111810-201606), baicalin (no. 110715-201720), and wogonin (no. 111514-201706) were purchased from the National Institutes for Food and Drug Control (Beijing, China). Forsythoside A, baicalin, and wogonin purity were found to be above $97.2 \%, 93.5 \%$, and $96.3 \%$, respectively. Other chemicals were of analytical grade and their purity was above $99.5 \%$.

2.2. Ethyl Acetate Extracts Preparation. A $0.1 \mathrm{~g}$ sample of Zhideke granules was weighed by using a XS205DU electronic balance (Mettler-Toledo, Switzerland) and extracted with $20 \mathrm{~mL}$ of water in an ultrasonic bath $(40 \mathrm{kHz}, 500 \mathrm{~W})$ for $30 \mathrm{~min}$. Then, the solutions were extracted twice with $20 \mathrm{~mL}$ ethyl acetate and combined two ethyl acetate extracts. Subsequently, these extracts were evaporated at the temperature of $80^{\circ} \mathrm{C}$ by water bath, and the residue was dissolved in $5 \mathrm{~mL}$ of methanol. Finally, the solution of the residue was filtered and was analysed.

2.3. The Sample Solution of HPLC Analysis. A $2.0 \mathrm{~g}$ sample of Zhideke granule was precisely weighed and extracted with $10 \mathrm{~mL}$ of methanol in an ultrasonic bath for $30 \mathrm{~min}$. Then, the extract was centrifuged at $13000 \mathrm{r} / \mathrm{min}$ for $10 \mathrm{~min}$ by using a TGL-16G centrifuge (Shanghai Anting Scientific Instrument Factory, China) and the supernatant was taken as the sample solution. Finally, the solution was analysed by HPLC.

2.4. Standards Preparation. We accurately weighed appropriate amounts of baicalin and wogonin, respectively, and then dissolved with methanol to prepare a mixture solution including two standards. Forsythoside A standard solution was prepared by dissolving $11.84 \mathrm{mg}$ each of accurately weighed pure compound in $5 \mathrm{~mL}$ methanol.

2.5. HPLC Chromatographic Conditions. Separation was achieved on Agilent ZORBAX Eclipse Plus-C18 column $(4.6 \times 250 \mathrm{~mm}, 5 \mu \mathrm{m})$. The mobile phase was methanol $(A)$ and $0.2 \%$ phosphoric acid $(B)$ by gradient elution $(0-30 \mathrm{~min}$, 5\%-20\% A; 30-50 min, 20\%-35\% A; 50-75 min, 35\%-40\% $A ; 75-110$ min, $40 \%-60 \% A ; 110-150$ min, $60 \%-90 \% A$ ) with photo-diode array (PDA) detection at $254 \mathrm{~nm}$ at the flow rate of $0.8 \mathrm{~mL} / \mathrm{min}$. The column temperature was $30^{\circ} \mathrm{C}$ and the volume was $10 \mu \mathrm{L}$.

2.6. UPLC Chromatographic Conditions. In the UPLC system, the column was a Thermo Hypersil Gold C18 column $(2.1 \mathrm{~mm} \times 100 \mathrm{~mm}, 1.9 \mu \mathrm{m})$. The mobile phase consisted of $0.1 \%$ formic acid acetonitrile (A) and $0.1 \%$ formic acid water containing $10 \mathrm{mmoL}$ of ammonium acetate (B) which was programmed with a gradient elution $(0-2.0 \mathrm{~min}, 5 \% A ; 2.0$ to $42.0 \mathrm{~min}, 5 \%$ to $95 \% A ; 42.0$ to $47.0 \mathrm{~min}, 95 \% A ; 47.1$ to $50 \mathrm{~min}, 95 \%$ to $5 \% A$ ) at a flow rate of $0.3 \mathrm{~mL} / \mathrm{min}$. The sample injection volume was $1 \mu \mathrm{L}$. The column temperature was maintained at $35^{\circ} \mathrm{C}$.

2.7. Instruments and MS Conditions. Chemical constituent's analyses were performed on Thermo Fisher U3000 UPLC system (Thermo Fisher, USA), Trace Finder software (Thermo Fisher, USA), which was used for the UPLC-Q-Exactive Orbitrap MS data processing. The ion source was the heated electrospray ionization (ESI). The electrospray ionization source in both positive and negative ion modes was used in MS analysis. Spray voltages were set at $3.5 \mathrm{kV}$ in a positive ion mode and $3.2 \mathrm{kV}$ in a negative ion mode, respectively. The auxiliary gas temperature was $300^{\circ} \mathrm{C}$, and the capillary temperature was $320^{\circ} \mathrm{C}$. MS data were obtained on Full MS/dd-MS2 mode in the mass range of $100-1500 \mathrm{Da}$. The resolution of the precursor mass was $70000 \mathrm{FWHM}$, while the resolution of the product mass was 17500 FWHM. The specific ion scan mode was off. High purity nitrogen was used as the collision gas, and nitrogen was used as spray gas. The flow rates of sheath gas and auxiliary gas were at the rate of 30 and $10 \mu \mathrm{L} / \mathrm{min}$, respectively.

\section{Results and Discussion}

We chose $50 \%$ ethyl acetate as the extraction solvent and identified chemical constituents from the ethyl acetate extract of Zhideke granules by UPLC-Q-Orbitrap MS in this paper. In the positive and negative ion modes, the total ion chromatograms of ethyl acetate extract in Zhideke granules are shown in Figure 1. The HPLC spectra of the standard of forsythoside A (A), the sample solution (B), a mixture of two standards (C), and the HPLC fingerprint of Zhideke granules (D) are shown in Figure 2.

According to MS mass, MS/MS fragmentation information, fragmentation patterns, and literature reports, we 


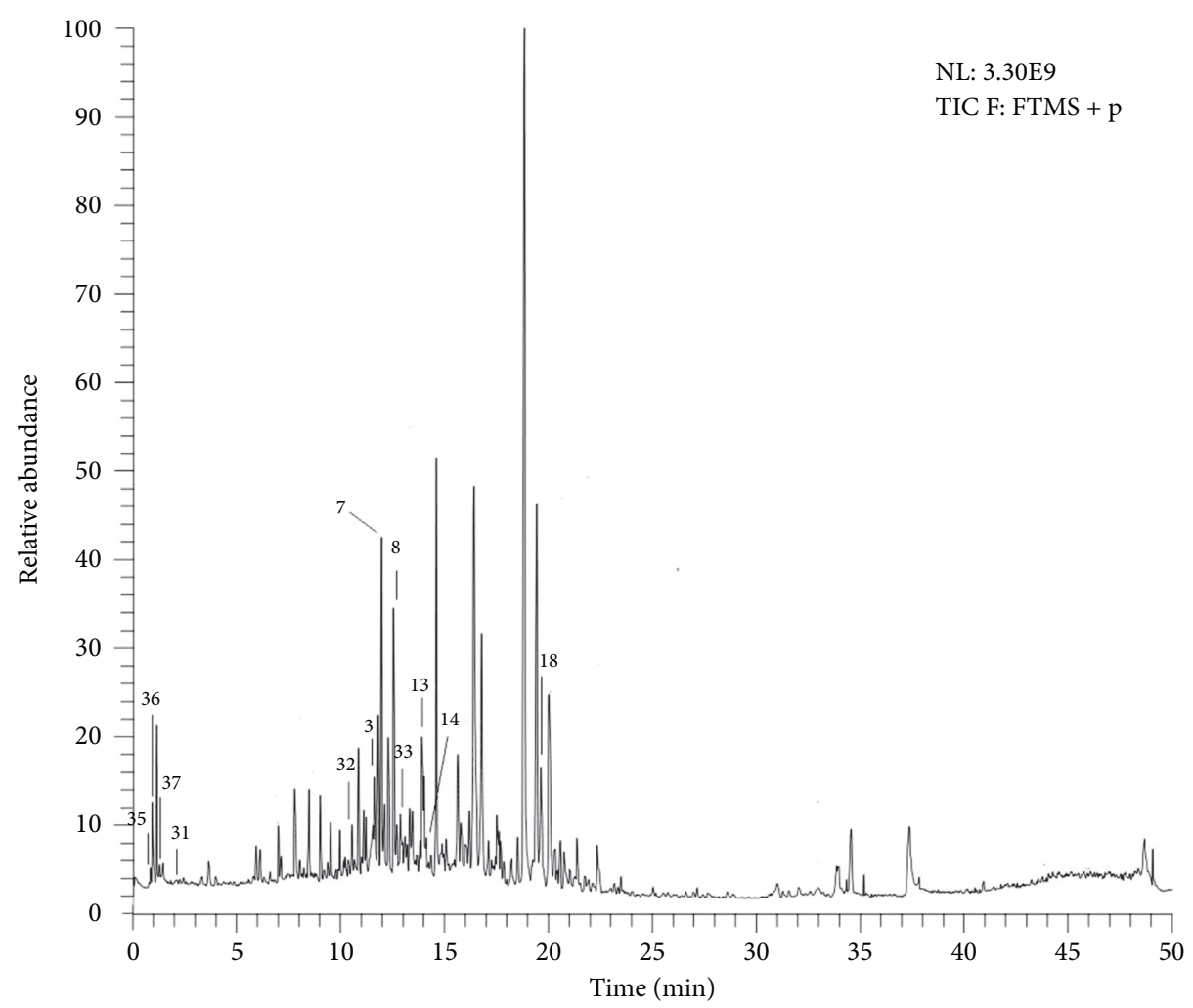

(a)

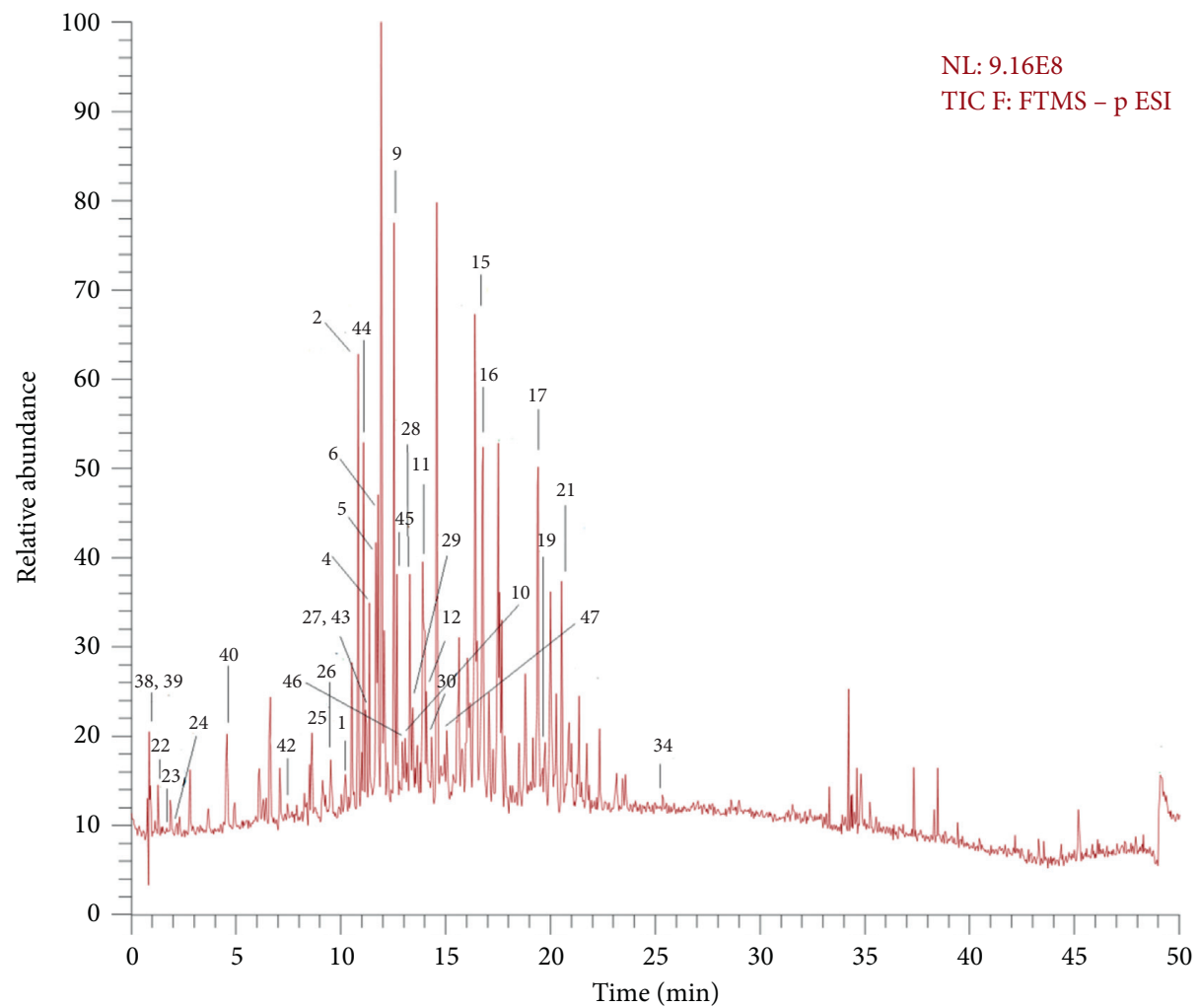

(b)

FIGURE 1: The total ion current chromatogram in positive (a) and negative ions (b). Mode for ethyl acetate of Zhideke granules. 


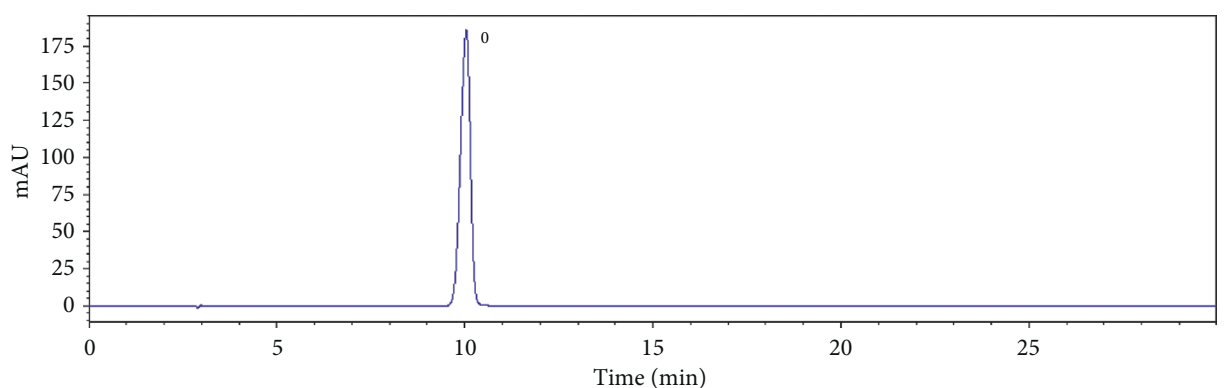

(a)

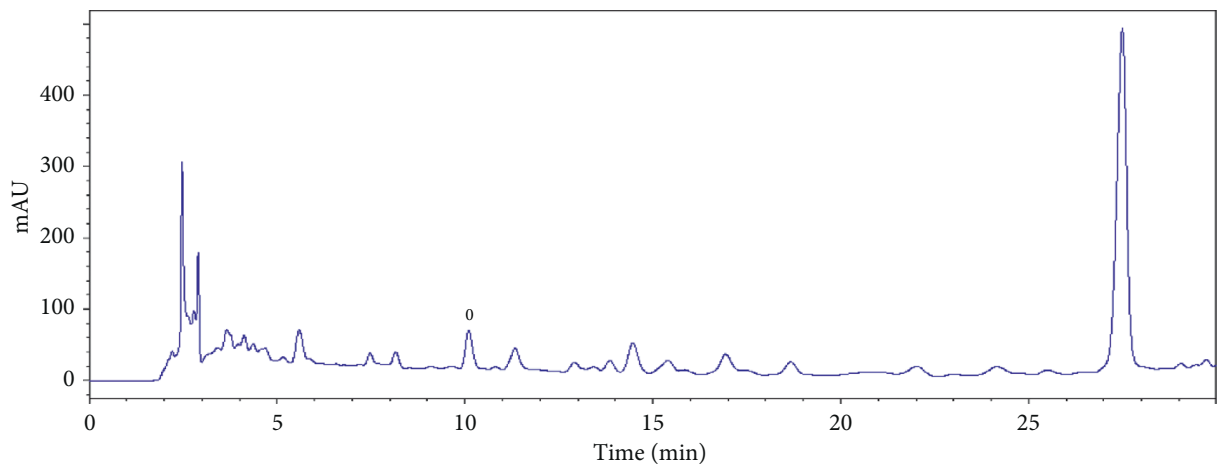

(b)

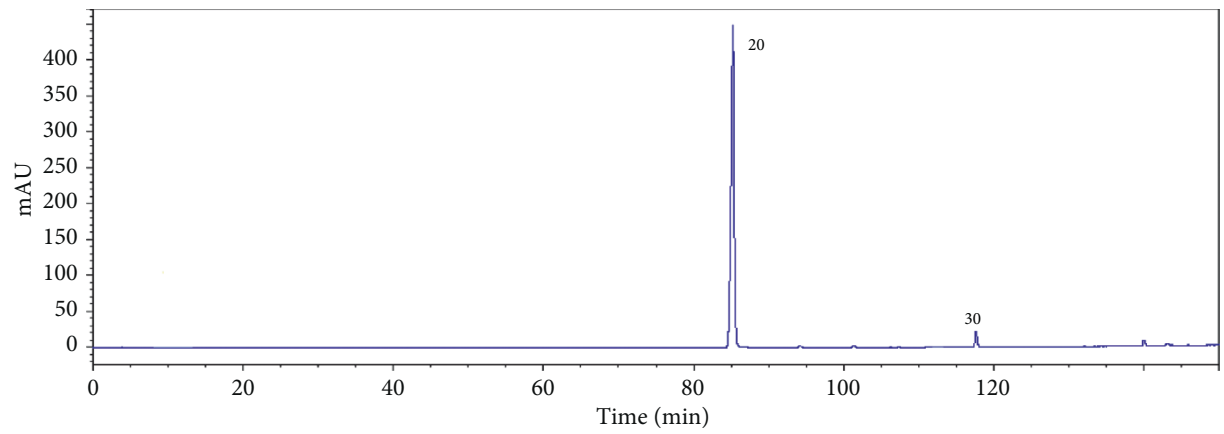

(c)

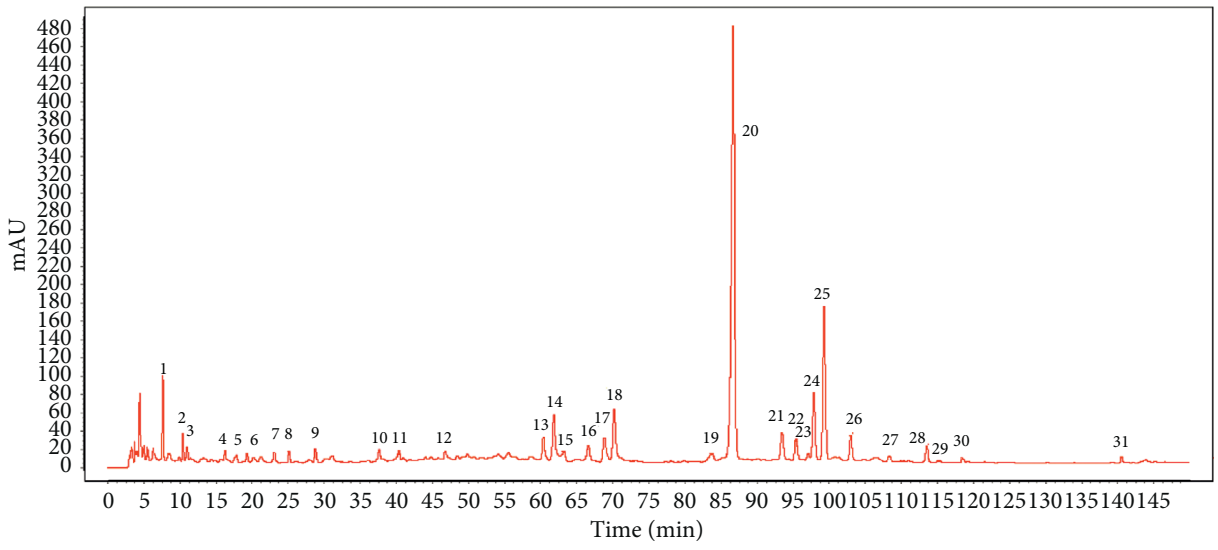

(d)

Figure 2: HPLC-UV (PDA) chromatograms obtained from the standard of forsythoside A (a), the sample solution (b), a mixture of two standards (c), and HPLC fingerprint of Zhideke granules (d). 
identified 47 possible chemical constituents including 21 flavonoids and glycosides, 9 organic acids, 4 volatile components, 3 nitrogen-containing compounds, and 10 other compounds from the ethyl acetate extract of Zhideke granules. The retention time, mass spectrometry information, and related literature of identified compounds are shown in Table 1.

3.1. Identification of Flavonoids and Glycosides. These compounds with a $\mathrm{C}_{6}-\mathrm{C}_{3}-\mathrm{C}_{6}$ carbon skeleton in the structure called flavonoids had two benzene rings formed by three carbon atoms. The structure of flavonoids often results in substituents such as hydroxyl, methyl, and methoxyl groups. Therefore, in the fragmentation regularity of flavonoids, these compounds easily lose neutral fragments of $\mathrm{CO}(28 \mathrm{Da}), \mathrm{H}_{2} \mathrm{O}$ (18 Da), $\mathrm{CO}_{2}(44 \mathrm{Da})$, and fragment ions of substituents [15]. In addition, the retro-Diels-Alder (RDA) fragmentation is a common fragmentation pattern in flavonoids. Taking compound 11 as an example, compound 11, with the quasimolecular ion $\mathrm{m} / z 301.0354[\mathrm{M}-\mathrm{H}]^{-}$and formula of $\mathrm{C}_{15} \mathrm{H}_{10} \mathrm{O}_{7}$, was identified as quercetin in the negative ionization mode. The fragment ion at $m / z 273.0396$ [M-H-CO] $^{-}$ was derived from the ion at the $m / z 301.0354$ by loss of a CO (28 Da) molecule in the MS/MS spectrum. The fragment ion at $m / z 178.9978\left[\mathrm{M}-\mathrm{H}-\mathrm{C}_{7} \mathrm{H}_{6} \mathrm{O}_{2}\right]^{-}$was from the ion at $\mathrm{m} / z$ 301.0354 because of the RDA fragmentation. Subsequently, fragment ions at $m / z 151.0031\left[\mathrm{M}-\mathrm{H}-\mathrm{C}_{7} \mathrm{H}_{6} \mathrm{O}_{2}-\mathrm{CO}\right]^{-}$and $m / z$ $107.0135\left[\mathrm{M}-\mathrm{H}-\mathrm{C}_{7} \mathrm{H}_{6} \mathrm{O}_{2}-\mathrm{CO}-\mathrm{CO}_{2}\right]^{-}$originated from the ion at $\mathrm{m} / z 178.9978$ by the loss of a CO $(28 \mathrm{Da})$ molecule and a $\mathrm{CO}_{2}(44 \mathrm{Da})$ molecule, respectively. Compound 11 was recognized as quercetin and the possible fragment pathway is as shown in Figure 3 according to these results [16]. Compound 17, with the quasimolecular ion $m / z 283.0602[\mathrm{M}-\mathrm{H}]^{-}$ and formula of $\mathrm{C}_{16} \mathrm{H}_{12} \mathrm{O}_{5}$, was characterized as wogonin by comparing with the reference. Compound 18, with the quasimolecular ion $\mathrm{m} / z 403.1387[\mathrm{M}+\mathrm{H}]^{+}$and formula of $\mathrm{C}_{15} \mathrm{H}_{10} \mathrm{O}_{7}$, was identified as nobiletin in the positive ionization mode. The ion at $m / z 373.0900\left[\mathrm{M}+\mathrm{H}-2 \mathrm{CH}_{3}\right]^{+}$was from the ion at $m / z 403.1387$ by loss of two methyl group fragments. Subsequently, the ion at $m / z$ 327.0849 [M+H$\left.2 \mathrm{CH}_{3}-\mathrm{H}_{2} \mathrm{O}-\mathrm{CO}\right]^{+}$originated from the ion at $\mathrm{m} / z 373.0900$ by loss of $\mathrm{H}_{2} \mathrm{O}(18 \mathrm{Da})$ and $\mathrm{CO}(28 \mathrm{Da})$. Compound 18 was characterized as nobiletin [17] according to these results.

According to the fragmentation process of flavonoids, we presumed that compounds $9,10,12,15,16,19,20$, and 21 were identified as scutellarein, eriodictyol, eupafolin, irigenin, baicalein, chrysin, pinocembrin, and tectorigenin, respectively.

In nature, flavonoids mostly exist in the form of glycosides. Glycosidic bonds easily cleavage in the fragmentation pattern of glycosides. Taking compound 3 as an example with the quasimolecular ion $m / z 417.1159[\mathrm{M}+\mathrm{H}]^{+}$ and formula of $\mathrm{C}_{21} \mathrm{H}_{20} \mathrm{O}_{9}$, it was identified as puerarin in the positive ionization mode. The ion at $\mathrm{m} / z$ 399.1055 [M+H$\left.\mathrm{H}_{2} \mathrm{O}\right]^{+}$was due to a natural loss of a $\mathrm{H}_{2} \mathrm{O}$ molecule $(18 \mathrm{Da})$. Subsequently, the ion at $m / z 297.07435\left[\mathrm{M}+\mathrm{H}-\mathrm{H}_{2} \mathrm{O}-\right.$ $\left.\mathrm{C}_{4} \mathrm{H}_{6} \mathrm{O}_{3}\right]^{+}$originated from the ion at $\mathrm{m} / z 373.0899$ by the loss of $\mathrm{C}_{4} \mathrm{H}_{6} \mathrm{O}_{3}(102 \mathrm{Da})$ fragment. Moreover, the fragment ion at $351.0837\left[\mathrm{M}+\mathrm{H}-2 \mathrm{H}_{2} \mathrm{O}-\mathrm{CH}_{2} \mathrm{O}\right]^{+}$came from the ion at $\mathrm{m} / z 399.1055$ by the loss of a $\mathrm{H}_{2} \mathrm{O}$ molecule $(18 \mathrm{Da})$ and $\mathrm{CH}_{2} \mathrm{O}$ fragment ion (39 Da). Fragment ions at $\mathrm{m} / z 267.0640$ $\left[\mathrm{M}+\mathrm{H}-2 \mathrm{H}_{2} \mathrm{O}-\mathrm{CH}_{2} \mathrm{O}-\mathrm{C}_{4} \mathrm{H}_{4} \mathrm{O}_{2}\right]^{+}$and $\mathrm{m} / z$ 307.0941 $[\mathrm{M}+\mathrm{H}-$ $\left.2 \mathrm{H}_{2} \mathrm{O}-\mathrm{C}_{2} \mathrm{H}_{4} \mathrm{O}\right]^{+}$were derived from the fragment ion $\mathrm{m} / z$ 351.0837 by the loss of a $\mathrm{C}_{4} \mathrm{H}_{4} \mathrm{O}_{2}(84 \mathrm{Da})$ fragment and a $\mathrm{C}_{2} \mathrm{H}_{4} \mathrm{O}(44 \mathrm{Da})$ fragment, respectively. The possible fragmented pathway of compound 3 is shown in Figure 4 according to this fragmental information. Thus, compound 3 was characterized as puerarin [18].

Compound 8, with the quasimolecular ion $\mathrm{m} / z 447.0902$ $[\mathrm{M}+\mathrm{H}]^{+}$and formula of $\mathrm{C}_{21} \mathrm{H}_{18} \mathrm{O}_{11}$, was identified as baicalin in the positive ion mode. The ion at $\mathrm{m} / z 447.0902$ produced the ion at $m / z 271.0588\left[\mathrm{M}+\mathrm{H}-\mathrm{C}_{6} \mathrm{H}_{8} \mathrm{O}_{6}\right]^{+}$after the loss of a glucuronic acid molecule $(177 \mathrm{Da})$. The fragmented ion $m / z$ 169.0124 $\left[\mathrm{M}+\mathrm{H}-\mathrm{C}_{6} \mathrm{H}_{8} \mathrm{O}_{6}-\mathrm{C}_{8} \mathrm{H}_{6}\right]^{+}$was from the ion at $m / z 271.0588$ by the loss of a $\mathrm{C}_{8} \mathrm{H}_{6}$ fragment ion $(102 \mathrm{Da})$. Subsequently, the ion at $\mathrm{m} / z 225.054[\mathrm{M}+\mathrm{H}-$ $\left.\mathrm{C}_{6} \mathrm{H}_{8} \mathrm{O}_{6}-\mathrm{C}_{8} \mathrm{H}_{6}-\mathrm{H}_{2} \mathrm{O}-\mathrm{CO}\right]^{+}$originates from the ion at $\mathrm{m} / z$ 271.0588 by loss of a $\mathrm{H}_{2} \mathrm{O}$ molecule $(18 \mathrm{Da})$ and a $\mathrm{CO}$ molecule $(28 \mathrm{Da})$. The possible fragment pathway of compound 8 is shown in Figure 5 according to this fragmental information. Compound 8 was baicalin by comparing with the reference standard and the literature report [15].

Based on the fragmentation patterns of glycosides, compounds $1,2,4,5,6,7,13,14$, and 20 were possibly identified as isoquercitrin, tectoridin, diosmin, hesperidin, luteolin 7-glucuronide, iridin, linarin, didymin, and pnocembrin, respectively.

\subsection{Identification of Organic Acids. Organic acids of Zhideke} granules are mainly found in Eriobotrya japonica (Thunb.), Platycodon grandiflorus (Jacq.) A. DC., Mentha haplocalyx Briq., etc. Organic acids mainly include two types, one of which is fatty acid and the other is aromatic acid. Organic acids easily lose neutral fragments of $\mathrm{CO}(28 \mathrm{Da}), \mathrm{H}_{2} \mathrm{O}$ $(18 \mathrm{Da}), \mathrm{CO}_{2}(44 \mathrm{Da})$, and a fragment of alkyl. Taking compound 24 as an example, compound 24, with the quasimolecular ion $\mathrm{m} / z$ 197.0448 $[\mathrm{M}-\mathrm{H}]^{-}$and formula of $\mathrm{C}_{9} \mathrm{H}_{10} \mathrm{O}_{5}$, was identified as danshensu under the negative ion mode. The fragment ion was at $m / z 179.0342\left[\mathrm{M}-\mathrm{H}-\mathrm{H}_{2} \mathrm{O}\right]^{-}$ at the loss of a $\mathrm{H}_{2} \mathrm{O}$ molecule. Fragment ions at $m / z 151.0401$ $\left[\mathrm{M}-\mathrm{H}-\mathrm{H}_{2} \mathrm{O}-\mathrm{CO}\right]^{-}$and $m / z 134.0369\left[\mathrm{M}-\mathrm{H}-\mathrm{H}_{2} \mathrm{O}-\mathrm{CO}_{2}\right]^{-}$were derived from the fragment ion $\mathrm{m} / z 179.0343$ by the loss of a $\mathrm{CO}(28 \mathrm{Da})$ molecule and a $\mathrm{CO}_{2}(44 \mathrm{Da})$ molecule, respectively. Based on fragment rules and literature, compound 24 was characterized as danshensu [19].

Compound 26, with the quasimolecular ion at $\mathrm{m} / \mathrm{z}$ $537.1024[\mathrm{M}-\mathrm{H}]^{-}$and formula of $\mathrm{C}_{27} \mathrm{H}_{22} \mathrm{O}_{12}$, was identified as lithospermic acid under the negative ion mode. The fragment ion at $m / z 493.1024[\mathrm{M}-\mathrm{H}]^{-}$was formed due to the loss of a $\mathrm{CO}_{2}(28 \mathrm{Da})$ molecule of the ion at $\mathrm{m} / z$ 537.1024. Fragment ions at $\mathrm{m} / z 295.0602\left[\mathrm{M}-\mathrm{H}-\mathrm{CO}_{2}-\mathrm{C}_{9} \mathrm{H}_{10} \mathrm{O}_{5}\right]^{-}$and $m / z 313.0711\left[\mathrm{M}-\mathrm{H}-\mathrm{C}_{9} \mathrm{H}_{8} \mathrm{O}_{4}\right]^{-}$were derived from the ion at $m / z 493.1027$ by the loss of fragment ions of $\mathrm{C}_{9} \mathrm{H}_{10} \mathrm{O}_{5}$ $(198 \mathrm{Da})$ and $\mathrm{C}_{9} \mathrm{H}_{8} \mathrm{O}_{4}(180 \mathrm{Da})$. According to the results, compound 26 was identified as lithospermic acid [20]. The fragmentation pathway is shown in Figure 6. 


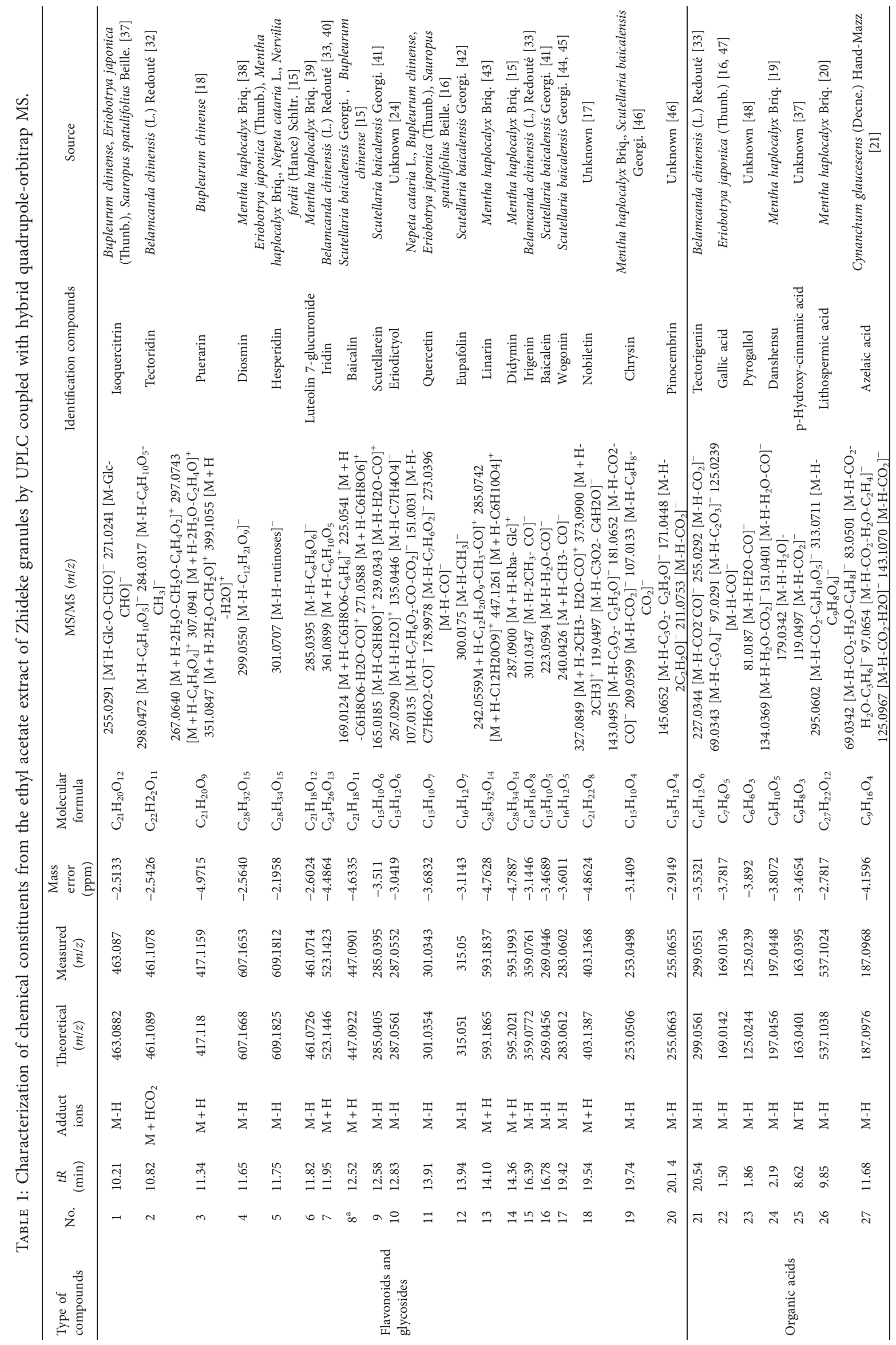




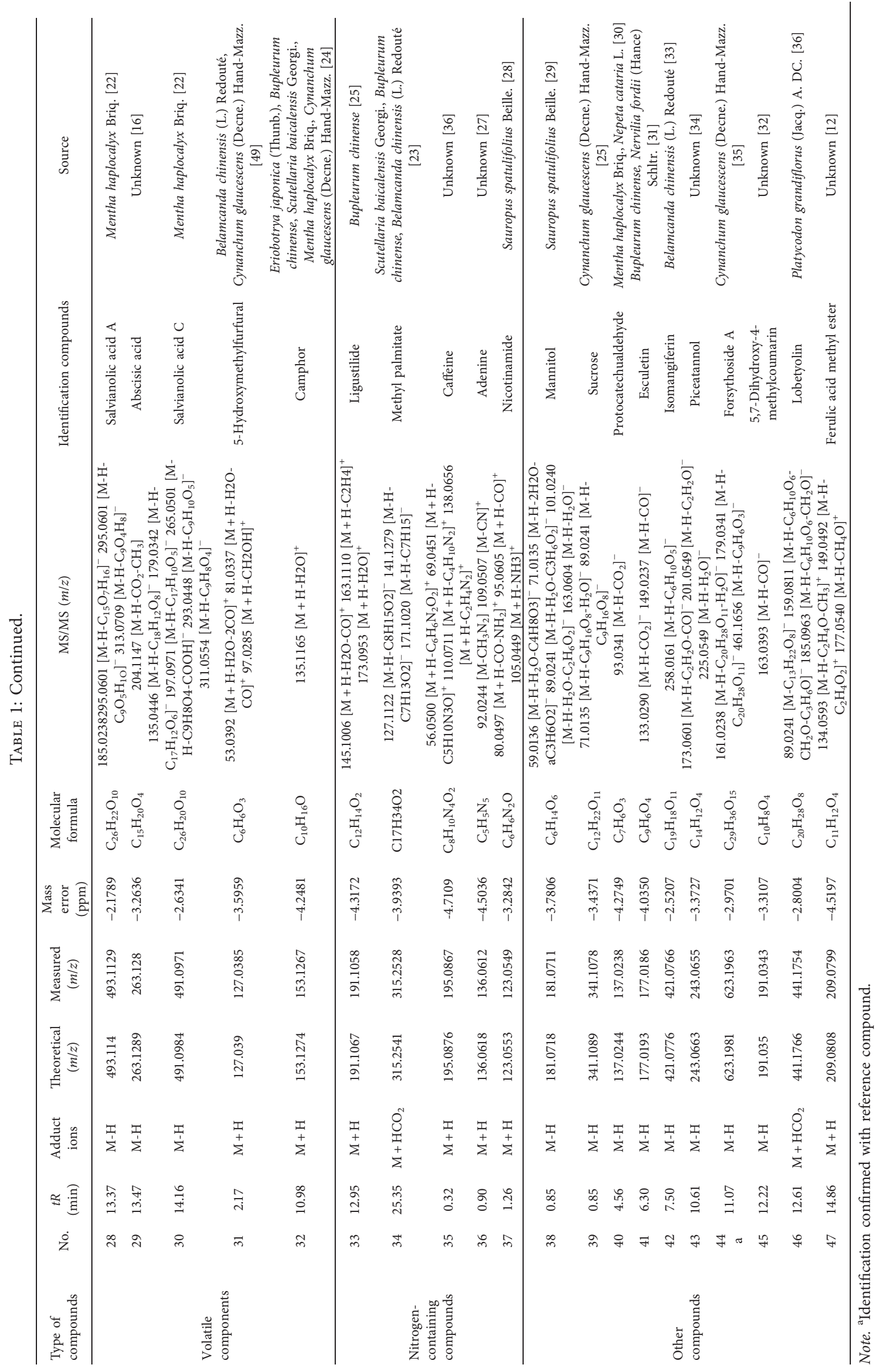


<smiles></smiles><smiles>Oc1cc(O)c2c(O)c(-c3ccc(O)c(O)c3)oc2c1</smiles>

$\mathrm{m} / \mathrm{z} 273.0396[\mathrm{M}-\mathrm{H}-\mathrm{CO}]^{-}$ $m / z 178.9978\left[\mathrm{M}-\mathrm{H}-\mathrm{C}_{7} \mathrm{H}_{6} \mathrm{O}_{2}\right]^{-}$

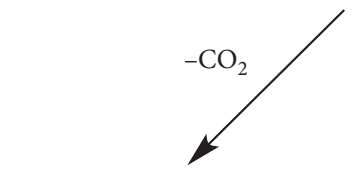

Figure 3: Possible fragmentation pathway of compound 11.<smiles>C[PH+](C)CCOC1OC(c2c(O)ccc3c(=O)c(-c4ccc(O)cc4)coc23)C(O)C(O)C1O</smiles>

$m / z 417.1159[\mathrm{M}+\mathrm{H}]^{+}$

$m / z 399.1055\left[\mathrm{M}+\mathrm{H}-\mathrm{H}_{2} \mathrm{O}\right]^{+}$

$m / z 297.0743\left[\mathrm{M}+\mathrm{H}-\mathrm{H}_{2} \mathrm{O}-\mathrm{C}_{4} \mathrm{H}_{6} \mathrm{O}_{3}\right]^{+}$

$$
-\mathrm{H}_{2} \mathrm{O} \downarrow-\mathrm{CH}_{2} \mathrm{O}
$$

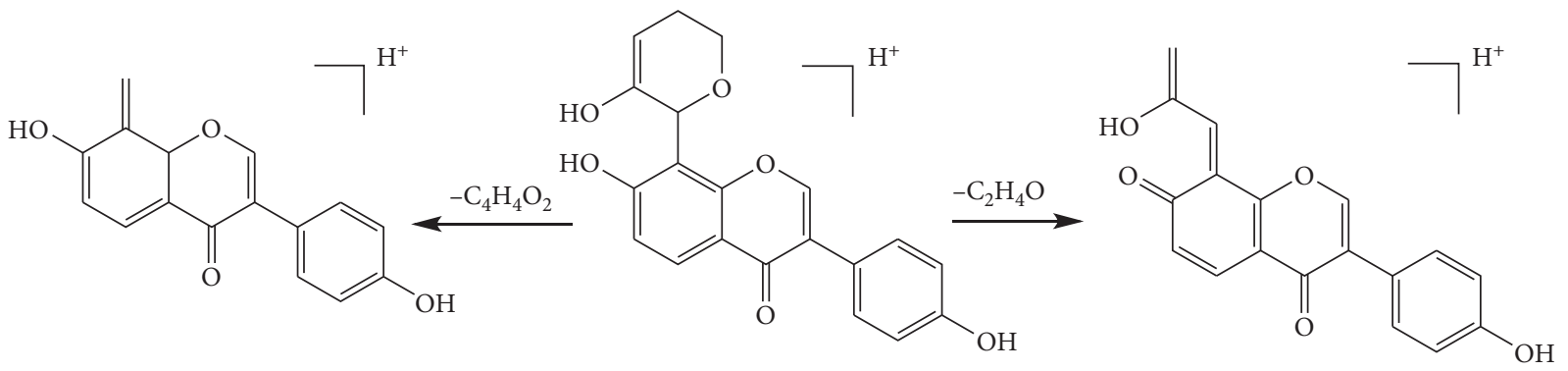

$m / z 267.0640\left[\mathrm{M}+\mathrm{H}-2 \mathrm{H}_{2} \mathrm{O}-\mathrm{CH}_{2} \mathrm{O}-\mathrm{C}_{4} \mathrm{H}_{4} \mathrm{O}_{2}\right]^{+} \quad m / z 351.0847\left[\mathrm{M}+\mathrm{H}-2 \mathrm{H}_{2} \mathrm{O}-\mathrm{CH}_{2} \mathrm{O}\right]^{+}$ $m / z 307.0941\left[\mathrm{M}+\mathrm{H}-2 \mathrm{H}_{2} \mathrm{O}-\mathrm{CH}_{2} \mathrm{O}-\mathrm{C}_{2} \mathrm{H}_{4} \mathrm{O}\right]^{+}$ Figure 4: Possible fragmentation pathway of compound 3. 


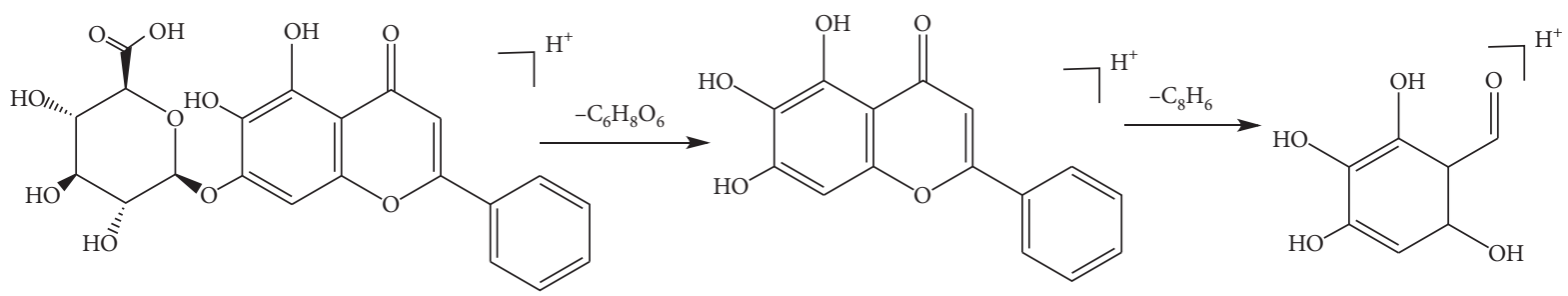

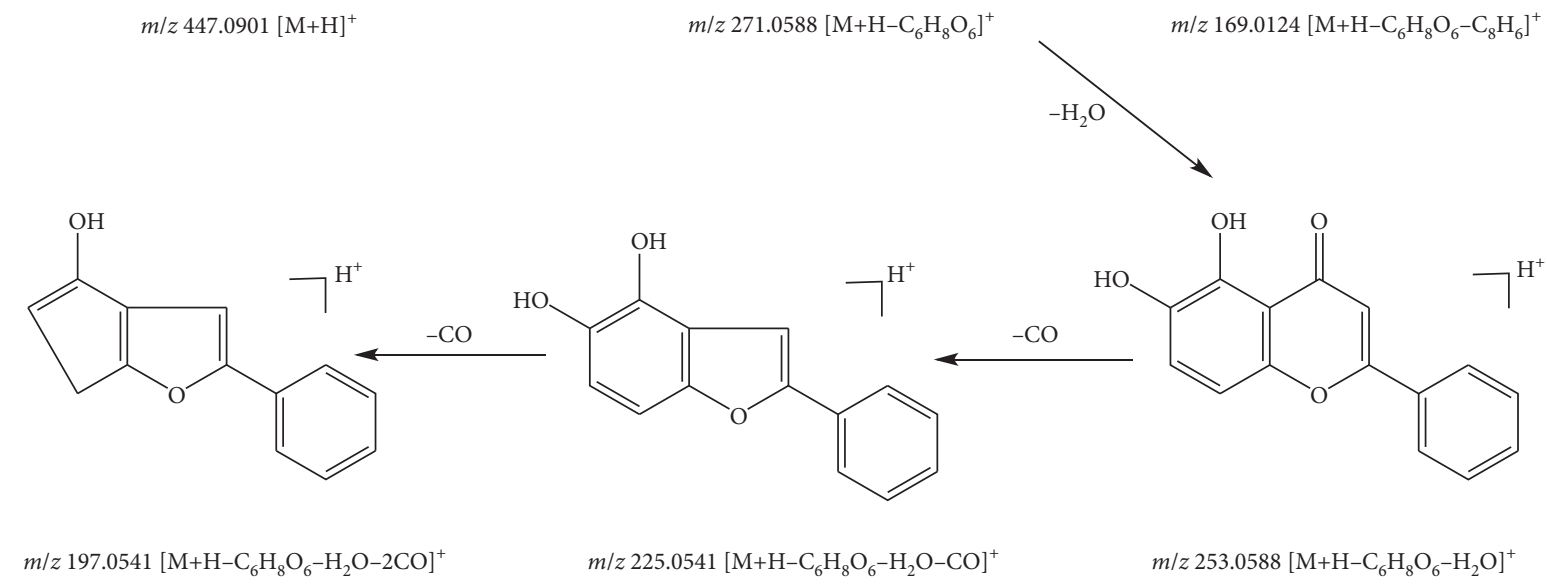

FIgURe 5: Possible fragmentation pathway of compound 8.

Compound 27, with the quasimolecular ion at $\mathrm{m} / \mathrm{z}$ $187.0968[\mathrm{M}-\mathrm{H}]^{-}$and formula of $\mathrm{C}_{9} \mathrm{H}_{16} \mathrm{O}_{4}$, was identified as azelaic acid under the negative ion mode. The fragment ion at $\mathrm{m} / z 143.1070\left[\mathrm{M}-\mathrm{H}-\mathrm{CO}_{2}\right]^{-}$was formed due to the loss of a $\mathrm{CO}_{2}$ $(28 \mathrm{Da})$ molecule of the ion at $\mathrm{m} / z 187.0968$. The fragment ion at $m / z 125.0967\left[\mathrm{M}-\mathrm{H}-\mathrm{CO}_{2}-\mathrm{H}_{2} \mathrm{O}\right]^{-}$was derived from the ion at $\mathrm{m} / z 143.1070$ by the loss of an $\mathrm{H}_{2} \mathrm{O}(18 \mathrm{Da})$ molecule. Subsequently, the fragment ions at $m / z 97.0654\left[\mathrm{M}-\mathrm{H}-\mathrm{CO}_{2}-\mathrm{H}_{2} \mathrm{O}-\right.$ $\left.\mathrm{C}_{2} \mathrm{H}_{4}\right]^{-}, \mathrm{m} / z$ 83.0501 $\quad\left[\mathrm{M}-\mathrm{H}-\mathrm{CO}_{2}-\mathrm{H}_{2} \mathrm{O}-\mathrm{C}_{3} \mathrm{H}_{6}\right]^{-}$, and $\mathrm{m} / \mathrm{z}$ $69.0342\left[\mathrm{M}-\mathrm{H}-\mathrm{CO}_{2}-\mathrm{H}_{2} \mathrm{O}-\mathrm{C}_{4} \mathrm{H}_{8}\right]^{-}$were derived from the ion at $\mathrm{m} / z 125.0967$ by the loss of fragment ions of $\mathrm{C}_{2} \mathrm{H}_{4}(28 \mathrm{Da})$, $\mathrm{C}_{3} \mathrm{H}_{6}(42 \mathrm{Da})$, and $\mathrm{C}_{4} \mathrm{H}_{8}$ (56), respectively. Based on MS data and related literature, compound 27 was identified as azelaic acid [21]. According to the fragmentation process [16], compound 29 was determined as abscisic acid.

Compound 30, with the quasimolecular ion at $\mathrm{m} / \mathrm{z}$ 491.0971 [M-H] $]^{-}$and formula of $\mathrm{C}_{26} \mathrm{H}_{20} \mathrm{O}_{10}$, was identified as salvianolic acid $\mathrm{C}$ under the negative ion mode. The fragment ions at $\mathrm{m} / \mathrm{z} 135.0446\left[\mathrm{M}-\mathrm{H}-\mathrm{C}_{18} \mathrm{H}_{12} \mathrm{O}_{8}\right]^{-}, 179.0342[\mathrm{M}-\mathrm{H}-$ $\left.\mathrm{C}_{17} \mathrm{H}_{12} \mathrm{O}_{6}\right]^{-}, \quad m / z \quad 197.0971 \quad\left[\mathrm{M}-\mathrm{H}-\mathrm{C}_{17} \mathrm{H}_{10} \mathrm{O}_{5}\right]^{-}$, and $\mathrm{m} / z$ $311.0554\left[\mathrm{M}-\mathrm{H}-\mathrm{C}_{9} \mathrm{H}_{8} \mathrm{O}_{4}\right]^{-}$were from the ion at $\mathrm{m} / z 491.0970$ by the loss of fragment ions $\mathrm{C}_{18} \mathrm{H}_{12} \mathrm{O}_{8}(356 \mathrm{Da}), \mathrm{C}_{17} \mathrm{H}_{12} \mathrm{O}_{6}$ (312 Da), $\mathrm{C}_{17} \mathrm{H}_{10} \mathrm{O}_{5}(294 \mathrm{Da})$, and $\mathrm{C}_{9} \mathrm{H}_{8} \mathrm{O}_{4}(180 \mathrm{Da})$, respectively. Subsequently, the fragment ion at $\mathrm{m} / \mathrm{z} 265.0501$ $\left[\mathrm{M}-\mathrm{H}-\mathrm{C}_{9} \mathrm{H}_{8} \mathrm{O}_{4}-\mathrm{COOH}\right]^{-}$was made up of the ion at $\mathrm{m} / \mathrm{z}$ 311.0554 by the loss of fragment ions of the carboxyl group fragment. The ion at $\mathrm{m} / z 293.0448\left[\mathrm{M}-\mathrm{H}-\mathrm{C}_{9} \mathrm{H}_{10} \mathrm{O}_{5}\right]^{-}$was from the cleavage of the ion at $\mathrm{m} / z 491.0970$ occurring in the position of the $\mathrm{C}-\mathrm{O}$ bond in the ester bond. Therefore, compound 30 was identified as salvianolic acid $\mathrm{C}$ by referring to the literature [22]. The fragmentation pathway of salvianolic acid $\mathrm{C}$ is shown in Figure 7. Based on fragment rules and literature [22], compound 28 was salvianolic acid A.
Based on the fragmentation rules of organic acids, compounds 22, 23, and 25 were identified as gallic acid, pyrogallol, and p-hydroxycinnamic acid, respectively.

3.3. Identification of Volatile Components. Volatile components are mainly found in Belamcanda chinensis (L.) Redouté, Cynanchum glaucescens (Decne.) Hand.-Mazz., and Bupleurum chinense in Zhideke granules. Taking compound 31 as an example, compound 31, with the quasimolecular ion at $\mathrm{m} / \mathrm{z}$ $127.0385[\mathrm{M}+\mathrm{H}]^{+}$and formula of $\mathrm{C}_{6} \mathrm{H}_{6} \mathrm{O}_{3}$, was identified as 5hydroxymethylfurfural in the positive ion mode. The fragment ion at $m / z 127.0385$ lost the $\mathrm{CH}_{2} \mathrm{OH}$ group (31 Da) and produced the fragment ion at $m / z 97.0285\left[\mathrm{M}+\mathrm{H}-\mathrm{CH}_{2} \mathrm{OH}\right]^{+}$. The fragment ion at $\mathrm{m} / z$ 81.0337[M+ $\left.\mathrm{H}-\mathrm{H}_{2} \mathrm{O}-\mathrm{CO}\right]^{+}$was derived from the ion at $\mathrm{m} / z 127.0385$ by the loss of a $\mathrm{H}_{2} \mathrm{O}(18 \mathrm{Da})$ molecule and a CO (28 Da) molecule, successively. Then, the fragment ion at $\mathrm{m} / \mathrm{z} 81.0337$ continuously lost a CO (28 Da) molecule and yielded the fragment ion at $m / z 53.0392[\mathrm{M}+\mathrm{H}-$ $\left.\mathrm{H}_{2} \mathrm{O}-2 \mathrm{CO}\right]^{+}$. Based on MS data and relevant literature [23], compound 31 was identified as 5-hydroxymethylfurfural.

Compound 32 showed $\mathrm{m} / z$ 153.1267 $[\mathrm{M}+\mathrm{H}]^{+}$ion and a formula of $\mathrm{C}_{10} \mathrm{H}_{16} \mathrm{O}$ in the positive ion mode of the first-order mass spectrum. In the MS/MS spectrum, we observed fragment ions at $\mathrm{m} / \mathrm{z} 59.0496,69.0701,93.0699,95.0854,97.0646$, $107.0854,109.1008$, and 135.1165. These results of fragmentation patterns are consistent with the relevant literature [24]. Thus, compound 32 was identified as camphor.

Compound 33, with the quasimolecular ion at $\mathrm{m} / \mathrm{z}$ $191.1058[\mathrm{M}+\mathrm{H}]^{+}$and formula of $\mathrm{C}_{12} \mathrm{H}_{14} \mathrm{O}$, was identified as ligustilide in the positive ion mode. Fragment ions at $\mathrm{m} / \mathrm{z}$ $163.1110\left[\mathrm{M}+\mathrm{H}-\mathrm{C}_{2} \mathrm{H}_{4}\right]^{+}$and $m / z 173.0953\left[\mathrm{M}+\mathrm{H}-\mathrm{H}_{2} \mathrm{O}\right]^{+}$ were from the ion at $\mathrm{m} / z 191.1058$ by the loss of $\mathrm{C}_{2} \mathrm{H}_{4}$ 
<smiles>C[CH+]CCc1c(C)cc(O)c2c1CC(c1ccc(O)c(O)c1)O2</smiles>

$$
m / z 295.0602\left[\mathrm{M}-\mathrm{H}-\mathrm{CO}_{2}-\mathrm{C}_{9} \mathrm{H}_{10} \mathrm{O}_{5}\right]^{+}
$$

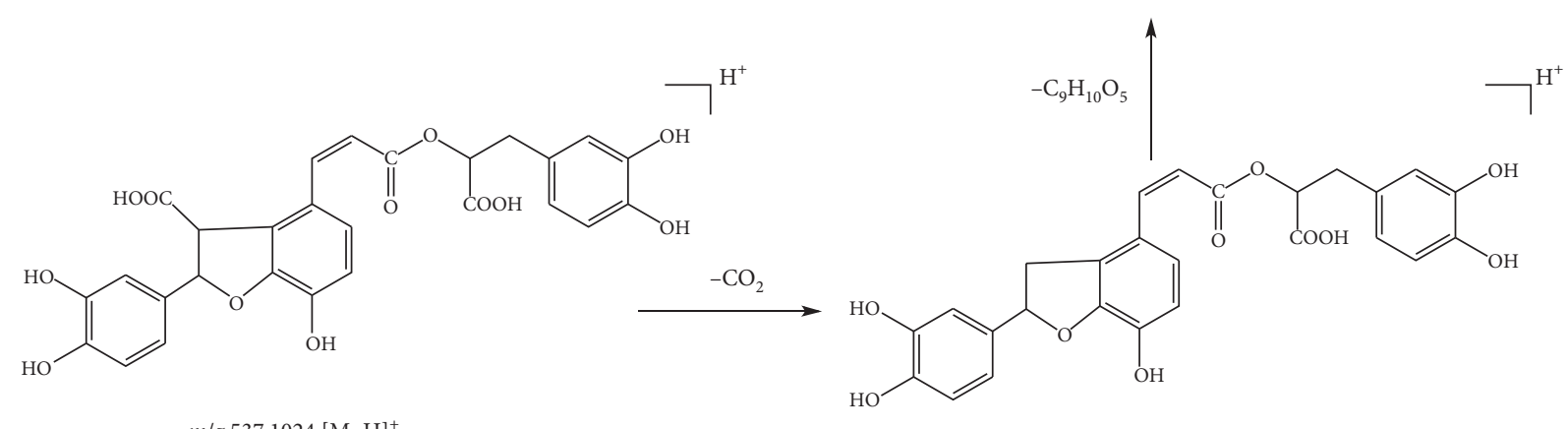
$m / z 537.1024[\mathrm{M}-\mathrm{H}]^{+}$

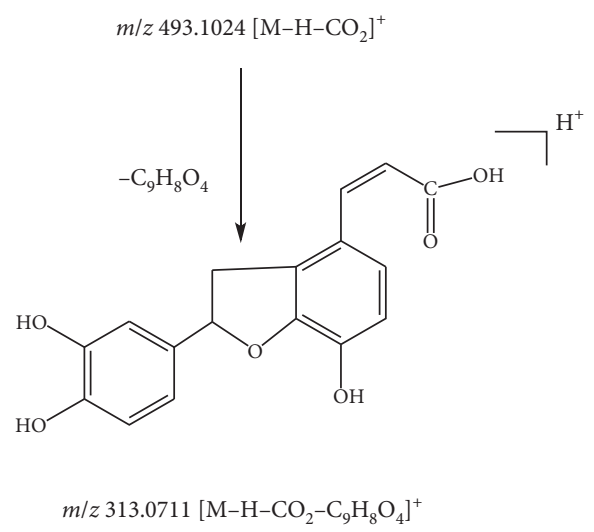

Figure 6: Possible fragmentation pathway of compound 26.

(28 Da) fragment and an $\mathrm{H}_{2} \mathrm{O}(18 \mathrm{Da})$ molecule, respectively. Subsequently, the fragment ion at $m / z 173.0953[\mathrm{M}+\mathrm{H}-$ $\mathrm{H}_{2} \mathrm{O}^{+}$was derived from the ion at $m / z 173.0953$ by the loss of a CO $(28 \mathrm{Da})$ molecule. According to relevant literature [25], compound 33 was identified as ligustilide. The fragmentation pathway of compound 33 is given in Figure 8.

Compound 34, with the quasimolecular ion at $\mathrm{m} / z$ 315.2528 $\left[\mathrm{M}+\mathrm{HCO}_{2}\right]^{-}$and formula of $\mathrm{C}_{17} \mathrm{H}_{34} \mathrm{O}_{2}$, was identified as methyl palmitate in the positive ion mode. Fragment ions at $\mathrm{m} / z 127.1122 \mathrm{C}_{9} \mathrm{H}_{19}{ }^{+}, \mathrm{m} / z 141.1279$ $\mathrm{C}_{10} \mathrm{H}_{21}{ }^{+}$, were formed because of cleavage of the alkyl group of the ester compounds. In addition, the fragment ion at $\mathrm{m} / z 171.1020\left[\mathrm{M}-\mathrm{H}-\mathrm{C}_{7} \mathrm{H}_{15}\right]^{-}$was derived from the $[\mathrm{M}-\mathrm{H}]^{-}$ion. Thus, compound 34 was identified as methyl palmitate based on the fragmentation rules and related reports [23].

3.4. Identification of Nitrogen-Containing Compounds. Nitrogen-containing compounds refer to a class of organic compounds containing a nitrogen element in the structure of the molecule and mainly include a nucleoside, an amino acid, and nicotinamide. The nitrogen-containing compounds are mainly derived from Mentha haplocalyx Briq. and Bupleurum chinense in Zhideke granules. The natural loss of $\mathrm{H}_{2} \mathrm{O}(18 \mathrm{Da})$, $\mathrm{CO}_{2}(44 \mathrm{Da})$, and $\mathrm{NH}_{3}(17 \mathrm{Da})$ molecules easily takes place in the fragmentation process of nitrogen-containing compounds. Besides, amino acid molecules easily lost the carboxyl group (45 Da) and a hydroxyl group $(17 \mathrm{Da})$.

Compound 35, with the quasimolecule ion at $\mathrm{m} / z 195.0867$ $[\mathrm{M}+\mathrm{H}]^{+}$and formula of $\mathrm{C}_{8} \mathrm{H}_{10} \mathrm{~N}_{4} \mathrm{O}_{2}$, was identified as caffeine in the positive ion mode. The fragment ions at $m / z 138.0656$ $\left[\mathrm{M}+\mathrm{H}-\mathrm{C}_{2} \mathrm{H}_{4} \mathrm{~N}_{2}\right]^{+}, \quad m / z \quad 110.0711 \quad\left[\mathrm{M}+\mathrm{H}-\mathrm{C}_{4} \mathrm{H}_{10} \mathrm{~N}_{2}\right]^{+}, \quad m / z$ $69.0451\left[\mathrm{M}+\mathrm{H}-\mathrm{C}_{5} \mathrm{H}_{10} \mathrm{~N}_{3} \mathrm{O}\right]^{+}$, and $m / z \quad 56.0500[\mathrm{M}+\mathrm{H}-$ $\left.\mathrm{C}_{6} \mathrm{H}_{6} \mathrm{~N}_{2} \mathrm{O}_{2}\right]^{+}$were derived from the fragment ion at $\mathrm{m} / z$ 195.0867 by the loss of the fragment ions of $\mathrm{C}_{2} \mathrm{H}_{4} \mathrm{~N}_{2}(56 \mathrm{Da})$, $\mathrm{C}_{4} \mathrm{H}_{10} \mathrm{~N}_{2} \quad(86 \mathrm{Da}), \mathrm{C}_{5} \mathrm{H}_{10} \mathrm{~N}_{3} \mathrm{O} \quad(128 \mathrm{Da})$, and $\mathrm{C}_{6} \mathrm{H}_{6} \mathrm{~N}_{2} \mathrm{O}_{2}$ $(138 \mathrm{Da})$, respectively. The fragmentation patterns are basically consistent with the literature [26]. Thus, compound 35 was identified as caffeine. According to the fragmentation pattern, compound 36 was identified as adenine [27]. 


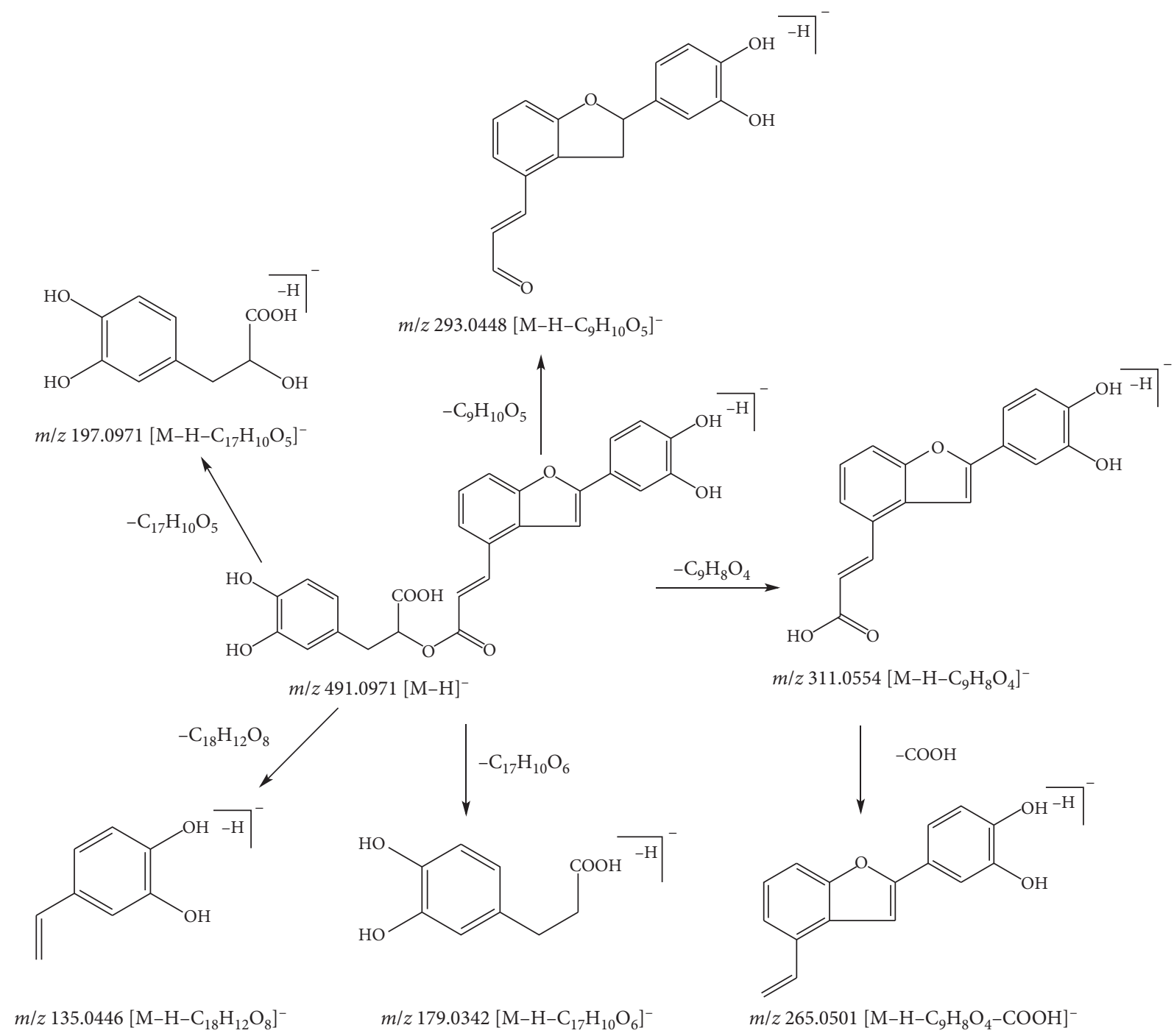

FIgURe 7: Possible fragmentation pathway of compound 30.

Compound 37, with the quasimolecule ion at $\mathrm{m} / z 123.0548$ $[\mathrm{M}+\mathrm{H}]^{+}$and formula of $\mathrm{C}_{6} \mathrm{H}_{6} \mathrm{~N}_{2} \mathrm{O}$, was identified as nicotinamide in the positive ion mode. The fragment ions at $105.0445\left[\mathrm{M}+\mathrm{H}-\mathrm{NH}_{3}\right]^{+}$and $m / z 95.0606[\mathrm{M}+\mathrm{H}-\mathrm{CO}]^{+}$were from the ion at $m / z 123.0548$ by the loss of a $\mathrm{NH}_{3}(17 \mathrm{Da})$ molecule fragment and a CO $(28 \mathrm{Da})$ molecule, respectively. Besides, the fragment ion at $m / z 80.0497\left[\mathrm{M}+\mathrm{H}-\mathrm{CO}-\mathrm{NH}_{2}\right]^{+}$ was formed owing to the loss of the $\mathrm{NH}_{2}(16 \mathrm{Da})$ fragment. Therefore, compound 37 was identified as nicotinamide [28].

3.5. Identification of Other Compounds. There were some other compounds in the Zhideke granules, except constituents mentioned in the previous discussion such as sugar, coumarin, and phenol. Taking 38 as an example, compound 38, with the quasimolecular ion at $\mathrm{m} / \mathrm{z}$ 181.0711 $[\mathrm{M}+\mathrm{H}]^{+}$and a formula of $\mathrm{C}_{6} \mathrm{H}_{14} \mathrm{O}_{6}$, was identified as mannitol in the positive ion mode. The fragment ion at $m / z 163.0670\left[\mathrm{M}-\mathrm{H}-\mathrm{H}_{2} \mathrm{O}\right]^{-}$was due to the loss of a $\mathrm{H}_{2} \mathrm{O}(18 \mathrm{Da})$ molecule of the ion at $\mathrm{m} / z 181.0711$.
The fragment ions at $m / z 101.0240\left[\mathrm{M}-\mathrm{H}-\mathrm{H}_{2} \mathrm{O}-\mathrm{C}_{2} \mathrm{H}_{6} \mathrm{O}_{2}\right]^{-}$, $m / z 59.0136\left[\mathrm{M}-\mathrm{H}-\mathrm{H}_{2} \mathrm{O}-\mathrm{C}_{4} \mathrm{H}_{8} \mathrm{O}_{3}\right]^{-}$, and $\mathrm{m} / z 89.0241[\mathrm{M}-$ $\left.\mathrm{H}-\mathrm{H}_{2} \mathrm{O}-\mathrm{C}_{3} \mathrm{H}_{6} \mathrm{O}_{2}\right]^{-}$were formed from the fragment ion at $m / z 163.0670$ by the loss of the fragment ions of $\mathrm{C}_{2} \mathrm{H}_{6} \mathrm{O}_{2}$ $(62 \mathrm{Da}), \mathrm{C}_{4} \mathrm{H}_{8} \mathrm{O}_{3}(104 \mathrm{Da})$, and $\mathrm{C}_{3} \mathrm{H}_{6} \mathrm{O}_{2}(74 \mathrm{Da})$, respectively. Subsequently, the fragment ion at $\mathrm{m} / z 89.0241$ $\left[\mathrm{M}-\mathrm{H}-\mathrm{H}_{2} \mathrm{O}-\mathrm{C}_{3} \mathrm{H}_{6} \mathrm{O}_{2}\right]^{-}$lost a $\mathrm{H}_{2} \mathrm{O}(18 \mathrm{Da})$ molecule and yielded $\mathrm{m} / z 71.0135\left[\mathrm{M}-\mathrm{H}-2 \mathrm{H}_{2} \mathrm{O}-\mathrm{C}_{3} \mathrm{H}_{6} \mathrm{O}_{2}\right]^{-}$. Taking the literature into account [29], compound 38 was identified as mannitol. The fragmentation pathway of mannitol is shown in Figure 9.

Compound 39 showed $m / z 341.1078[\mathrm{M}-\mathrm{H}]^{-}$ion and a formula of $\mathrm{C}_{12} \mathrm{H}_{22} \mathrm{O}_{11}$ in the negative ion mode of the firstorder mass spectrum. In the MS/MS spectrum, the fragment ions at $\mathrm{m} / \mathrm{z}$ 59.0136, 71.0136, 89.0241, 95.0137, and 113.0241 were obtained. These fragmentation patterns were consistent with the literature report [25]. Therefore, compound 39 was recognized as sucrose.

Compound 40, with the quasimolecular ion at $\mathrm{m} / \mathrm{z}$ $137.0238[\mathrm{M}-\mathrm{H}]^{-}$and formula of $\mathrm{C}_{7} \mathrm{H}_{6} \mathrm{O}_{3}$, was identified as 

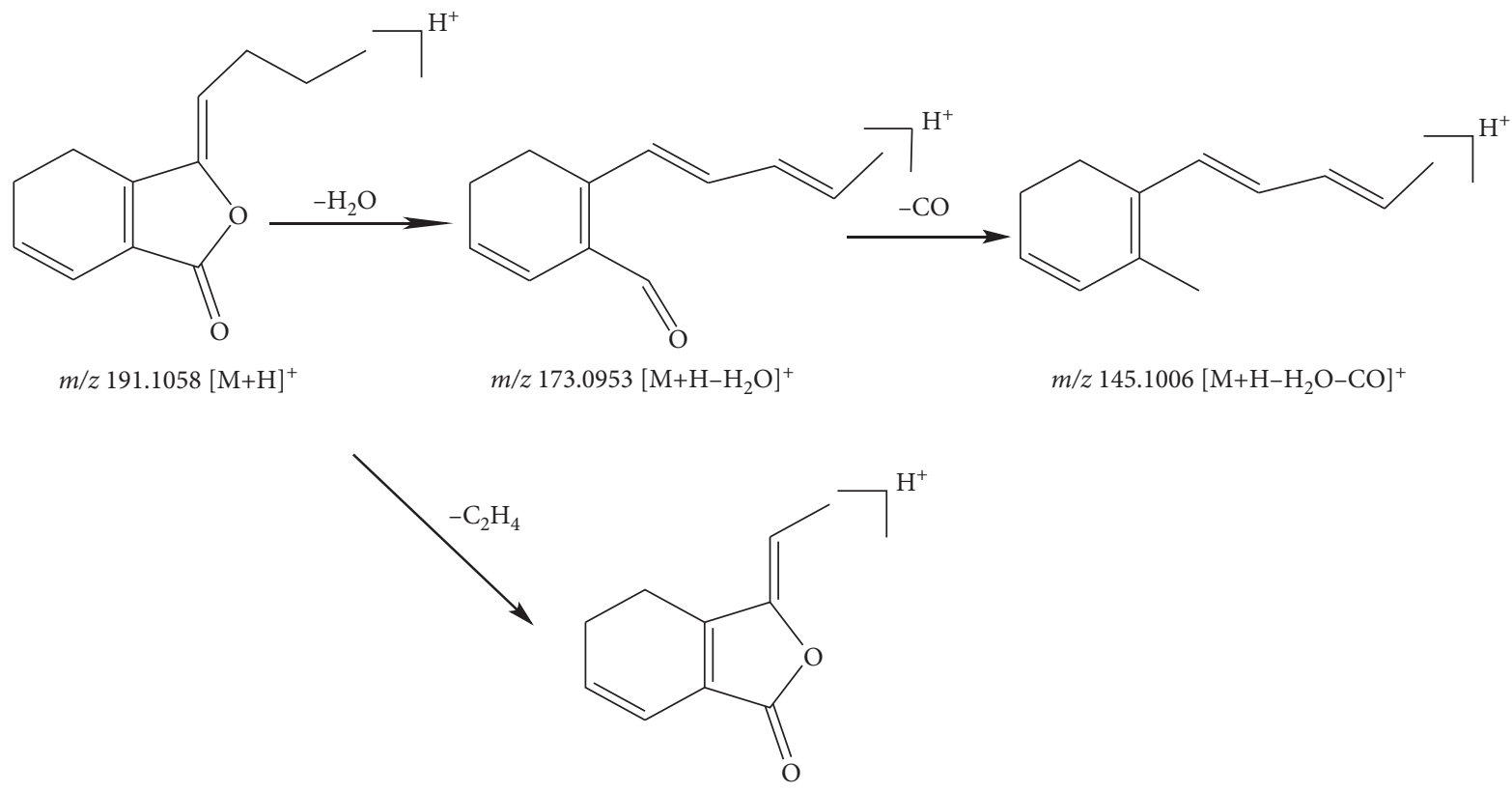

$m / z 163.1110\left[\mathrm{M}+\mathrm{H}-\mathrm{C}_{2} \mathrm{H}_{4}\right]^{+}$

FIgURe 8: Possible fragmentation pathway of compound 33.

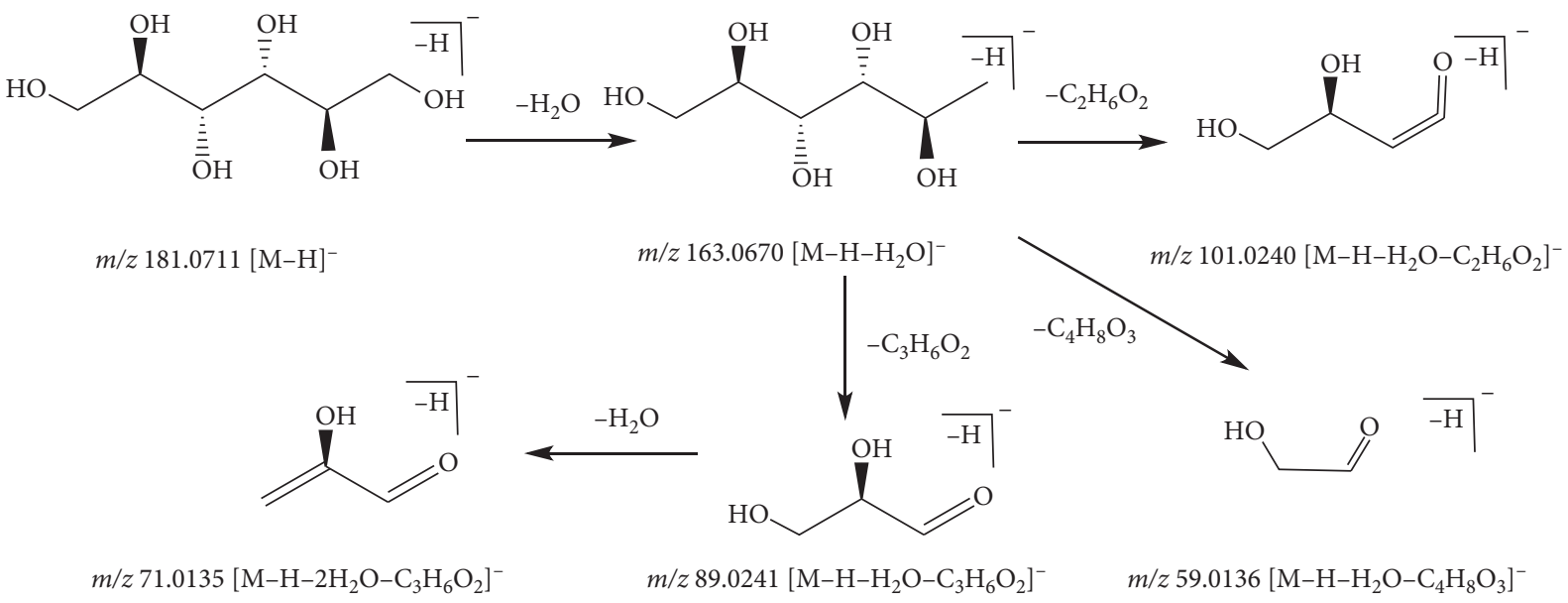

FIgURE 9: Possible fragmentation pathway of compound 38.

protocatechualdehyde in the negative ion mode. The characteristic fragment ion at $\mathrm{m} / z 93.0341\left[\mathrm{M}-\mathrm{H}-\mathrm{CO}_{2}\right]^{-}$originates from the ion at $\mathrm{m} / z 137.0238$ by the loss of a $\mathrm{CO}_{2}$ (44 Da) molecule. Based on the reported literature [30], compound 40 was identified as protocatechualdehyde.

Compound 41, with the quasimolecular ion at $\mathrm{m} / z 177.0186$ $[\mathrm{M}-\mathrm{H}]^{-}$and formula of $\mathrm{C}_{9} \mathrm{H}_{6} \mathrm{O}_{4}$, was identified as esculetin in the negative ion mode. Fragment ions at $m / z 133.0290[\mathrm{M}-\mathrm{H}-$ $\mathrm{CO} 2]^{-}$and $\mathrm{m} / z$ 149.0237 $[\mathrm{M}-\mathrm{H}-\mathrm{CO}]^{-}$were derived from the fragment ion at $m / z 177.0186$ by the loss of a $\mathrm{CO}_{2}(44 \mathrm{Da})$ molecule and a CO $(28 \mathrm{Da})$ molecule, respectively. Thus, compound 41 was identified as esculetin [31]. Meanwhile, compound 45 was identified as 5,7-dihydroxy-4-methyl coumarin according to the fragmentation pattern [32].
Compound 42, with the quasimolecular ion at $\mathrm{m} / \mathrm{z}$ $421.0766[\mathrm{M}-\mathrm{H}]^{-}$and formula of $\mathrm{C}_{19} \mathrm{H}_{18} \mathrm{O}_{11}$, was identified as isomangiferin in the negative ion mode. The fragment ion at 258.0161 $\left[\mathrm{M}-\mathrm{H}-\mathrm{C}_{6} \mathrm{H}_{10} \mathrm{O}_{5}\right]^{-}$was formed from the cleavage of the ion at $m / z 421.0766$ occurring in the position of the glucoside bond by the loss of the $\mathrm{C}_{6} \mathrm{H}_{10} \mathrm{O}_{5}(162 \mathrm{Da})$ fragment ion. Therefore, compound 42 was identified as isomangiferin [33].

Compound 43, with the quasimolecular ion at $\mathrm{m} / \mathrm{z}$ $243.0655[\mathrm{M}-\mathrm{H}]^{-}$and formula of $\mathrm{C}_{14} \mathrm{H}_{12} \mathrm{O}_{4}$, was identified as piceatannol in the negative ion mode. The fragment ions at $m / z 225.0549$ [M-H- $\left.\mathrm{H}_{2} \mathrm{O}\right]^{-}, m / z 159.0445\left[\mathrm{M}-\mathrm{H}-\mathrm{C}_{4} \mathrm{H}_{4} \mathrm{O}_{2}\right.$ ], and $m / z 201.0549$ [M-H- $\left.\mathrm{C}_{2} \mathrm{H}_{2} \mathrm{O}\right]^{-}$originated from the ion at $\mathrm{m} / z 243.0655$ by the loss of a $\mathrm{H}_{2} \mathrm{O}(18 \mathrm{Da})$ molecule, 

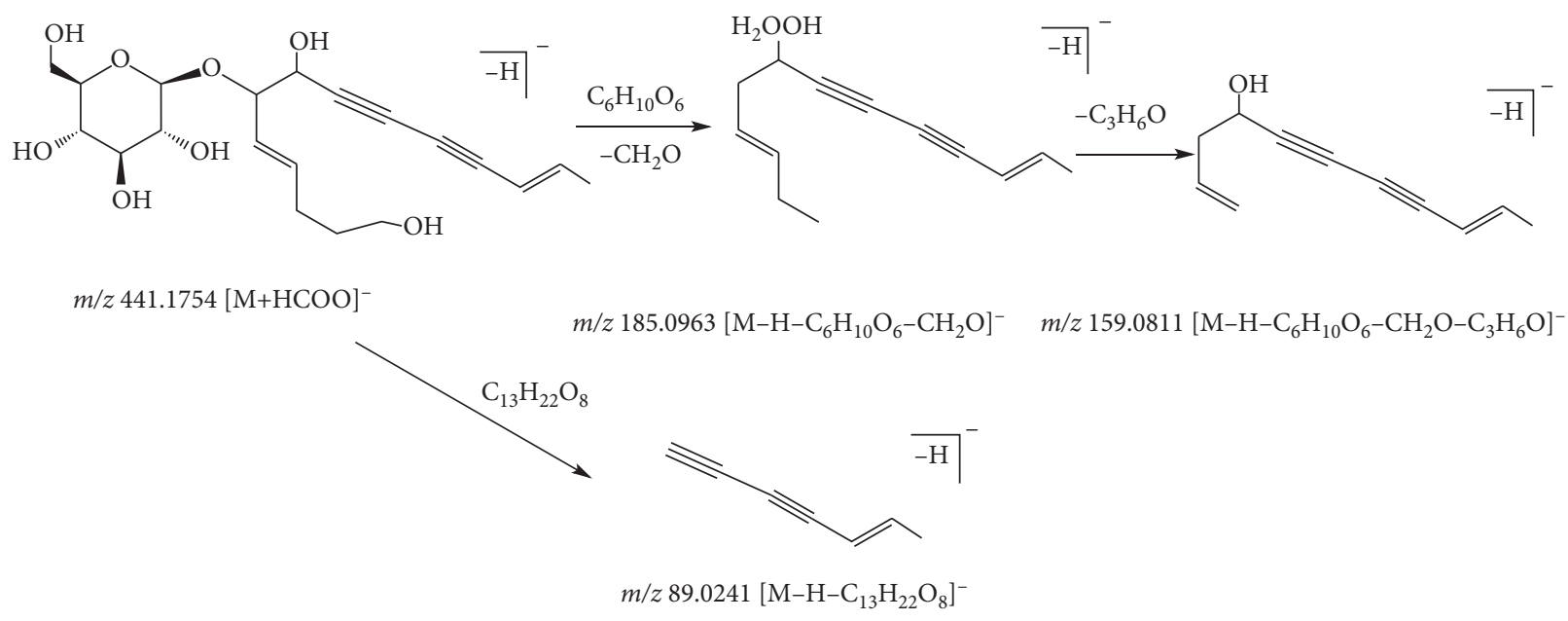

FIgURE 10: Possible fragmentation pathway of compound 46.

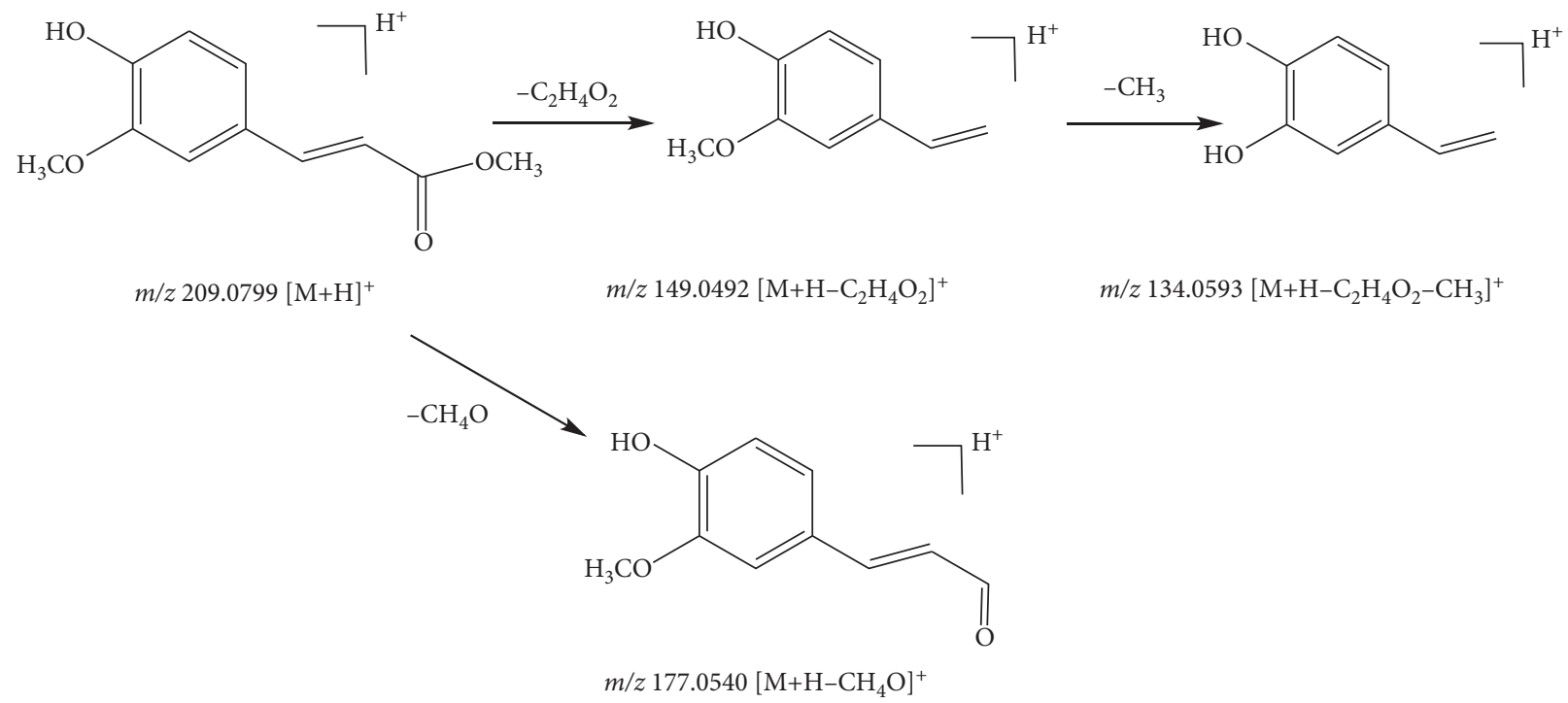

Figure 11: Possible fragmentation pathway of compound 47.

a $\mathrm{C}_{4} \mathrm{H}_{4} \mathrm{O}_{2}(84 \mathrm{Da})$ fragment, and $\mathrm{C}_{2} \mathrm{H}_{2} \mathrm{O}(42 \mathrm{Da})$ fragment. Subsequently, the fragment ion $m / z 173.0601\left[\mathrm{M}-\mathrm{H}-\mathrm{C}_{2} \mathrm{H}_{2} \mathrm{O}-\right.$ $\mathrm{CO}]^{-}$was formed from the ion at $\mathrm{m} / z 201.0549$ [M-H$\left.\mathrm{C}_{2} \mathrm{H}_{2} \mathrm{O}\right]^{-}$due to a $\mathrm{CO}(28 \mathrm{Da})$ molecule. Compound 43 was identified as piceatannol [34].

Compound 44 showed $\mathrm{m} / z$ 623.1963[M-H] $]^{-}$ion and a formula of $\mathrm{C}_{29} \mathrm{H}_{36} \mathrm{O}_{15}$ in the negative ion mode of the firstorder mass spectrum. Fragment ions at $m / z 461.1656$ [M-H$\left.\mathrm{C}_{9} \mathrm{H}_{6} \mathrm{O}_{3}\right]^{-}$and $m / z$ 179.0341 [M-H- $\left.{ }_{20} \mathrm{H}_{28} \mathrm{O}_{11}\right]^{-}$were derived from the fragment ion at $\mathrm{m} / z 623.1966$ by the loss of the fragments $\mathrm{C}_{9} \mathrm{H}_{6} \mathrm{O}_{3}(162 \mathrm{Da})$ and $\mathrm{C}_{20} \mathrm{H}_{28} \mathrm{O}_{11}(444 \mathrm{Da})$, respectively. Furthermore, the fragment ion at $\mathrm{m} / z 179.0341$ lost a $\mathrm{H}_{2} \mathrm{O}(18 \mathrm{Da})$ molecule and yielded the fragment ion at $m / z 161.0238\left[\mathrm{M}-\mathrm{H}-\mathrm{C}_{20} \mathrm{H}_{28} \mathrm{O}_{11}-\mathrm{H}_{2} \mathrm{O}\right]^{-}$. Based on relevant literature [35], compound 44 may be forsythoside A, isoacteoside, or verbascoside. Then, compound 44 was identified as forsythoside A by comparing with the reference standard.

Compound 46, with the quasimolecular ion at $\mathrm{m} / \mathrm{z}$ $441.1754[\mathrm{M}+\mathrm{HCOOH}]^{-}$and formula of $\mathrm{C}_{20} \mathrm{H}_{28} \mathrm{O}_{8}$, was identified as lobetyolin in the negative ion mode. The fragment ion at $m / z 185.0963\left[\mathrm{M}-\mathrm{H}-\mathrm{C}_{6} \mathrm{H}_{10} \mathrm{O}_{6}-\mathrm{CH}_{2} \mathrm{O}\right]^{-}$was derived from the ion at $m / z 441.1754$ by the loss of a fragment of the $\mathrm{C}_{6} \mathrm{H}_{10} \mathrm{O}_{6}(178 \mathrm{Da})$ and $\mathrm{CH}_{2} \mathrm{O}(30 \mathrm{Da})$ groups. Subsequently, the fragment ion at $\mathrm{m} / z$ 159.0811 [M-H$\left.\mathrm{C}_{6} \mathrm{H}_{10} \mathrm{O}_{6}-\mathrm{CH}_{2} \mathrm{O}-\mathrm{C}_{3} \mathrm{H}_{6} \mathrm{O}\right]^{-}$originated from the ion at $\mathrm{m} / z$ 185.0963 by the loss of $\mathrm{C}_{3} \mathrm{H}_{6} \mathrm{O}(58 \mathrm{Da})$ fragment. In addition, the fragment ion at $m / z 89.0241\left[\mathrm{M}-\mathrm{C}_{13} \mathrm{H}_{22} \mathrm{O}_{8}\right]^{-}$was formed from the ion at $m / z 441.1754$ by the loss of $\mathrm{C}_{13} \mathrm{H}_{22} \mathrm{O}_{8}$ fragment. Thus, compound 46 was identified as lobetyolin [36]. The fragmentation pathway of lobetyolin is shown in Figure 10. 
Compound 47, with the quasimolecular ion at $\mathrm{m} / \mathrm{z}$ 209.0799 $[\mathrm{M}+\mathrm{H}]^{+}$and formula of $\mathrm{C}_{11} \mathrm{H}_{12} \mathrm{O}_{4}$, was identified as methyl 4-hydroxy-3-methoxycinnamate in the positive ion mode. Fragment ions at $m / z 177.0540\left[\mathrm{M}-\mathrm{H}-\mathrm{CH}_{4} \mathrm{O}\right]^{+}$ and $m / z 149.0492\left[\mathrm{M}-\mathrm{H}-\mathrm{C}_{2} \mathrm{H}_{4} \mathrm{O}_{2}\right]^{+}$were derived from the ion at $\mathrm{m} / z 209.0799$ by the loss of fragments of $\mathrm{CH}_{4} \mathrm{O}$ (32 Da) and $\mathrm{C}_{2} \mathrm{H}_{4} \mathrm{O}_{2}(60 \mathrm{Da})$. Subsequently, the fragment ion at $m / z 134.0593\left[\mathrm{M}-\mathrm{H}-\mathrm{C}_{2} \mathrm{H}_{4} \mathrm{O}-\mathrm{CH}_{3}\right]^{+}$was formed from the ion at $m / z 149.0492$ by loss of the $\mathrm{CH}_{3}(15 \mathrm{Da})$ fragment. Therefore, compound 47 was identified as ferulic acid methyl ester [12]. The fragmentation pathway of ferulic acid methyl ester is shown in Figure 11.

\section{Conclusions}

The paper provided a new analysis method for the chemical constituents research of Zhideke granules. At the same time, this study rapidly and systematically analysed the chemical constituents of Zhideke granules by UPLC coupled with hybrid quadrupole-orbitrap MS. 47 chemical constituents were identified by UPLC-Q-Orbitrap HRMS including flavonoids and glycosides, organic acids, volatile components, nitrogen-containing compounds, sugars, and coumarins, which will provide a reference for quality control of Zhideke granules, and further reveal the pharmacodynamic substances of Zhideke granules.

\section{Data Availability}

The data used to support the findings of this study are available from the corresponding author upon request.

\section{Conflicts of Interest}

The authors declare that there are no conflicts of interest regarding the publication of this paper.

\section{Acknowledgments}

Financial support was provided by Special Fund Project for Innovation Driven Development of Guangxi (AA17202046), The First-Class Subject of Traditional Chinese Medicine (Ethnic Pharmacy) in Guangxi ([2018]12), Collaborative Innovation Center of Zhuang and Yao Medicine ([2013]20), Guangxi Province Key Laboratory of Zhuang and Yao Medicine ([2014]32), The Eighth Batch of Special Experts Project of Guangxi Zhuang Autonomous Region (Study on quality standard of Zhuang and Yao medicine, [2019]13), Cultivating High-Level Talent Teams in the Qi Huang Project of Guangxi University of Chinese Medicine (2018002), Program for Innovative Research Team of High Education and Outstanding Scholar in Guang Xi ([2019]52), and Guangxi One Thousand Young and Middle-Aged College and University Backbones Teachers Cultivation Program ([2019]5).

\section{References}

[1] J. Xin, L. L. Li, and A. S. Ling, "Clinical observation of Zhideke granules in treating acute attack of bronchial asthma," Journal of Guangxi University of Chinese Medicine, vol. 16, no. 1, pp. 35-36, 2013.

[2] M. Huang, G. D. Huang, Y. L. Wei et al., "Study on the quality standard of Zhideke granules," China Medical Herald, vol. 15, no. 30, pp. 106-110+182, 2018.

[3] H. M. Yang, S. N. Chen, L. Pan et al., "Clinical study of Zhideke granule in treating cough variant asthma of windheat attacks the lung type complicated with mycoplasma infection," Lishizhen Medicine and Materia Medica Research, vol. 31, no. 5, pp. 1150-1151, 2020.

[4] C. Han, L. Yang, Q. L. Zhang et al., "Correlation study on baicalin's anti-asthmatic effects and HMGB1/TLR4 signal pathway," World Chinese Medicine, vol. 14, no. 6, pp. 14021407, 2019.

[5] C. Han, L. Yang, Q. L. Zhang et al., "Effect of baicalin on airway remodeling of bronchial asthma," World Chinese Medicine, vol. 22, no. 7, pp. 749-754, 2017.

[6] G. Chen, G. Y. Guo, L. B. Zhang et al., "Effects of blackberrylily on bronchail asthma patients and eosinophil degranuler in vitro," World Chinese Medicine, vol. 21, no. 12, pp. 1026-1029, 2007.

[7] Y. N. Wei and W. P. Wang, "Progress on the pharmacological effects of Belamcanda chinensis (L.) Redouté," Scientific and Technological Innovation, vol. 19, p. 22, 2011.

[8] L. X. He, Y. J. Wang, Q. Q. Zhang et al., "Identification of chemical components of gardenia water extract by UPLC Qexactive orbitrap MS," Guangzhou Chemical Industry, vol. 48, no. 5, pp. 94-97, 2020.

[9] J. Y. Sheng, H. L. Zhou, L. B. Zhang et al., "Analysis on chemical constituents of fruit of Chaenomeles speciosa by UPLC-Q-exactive orbitrap-MS," Chinese Traditional and Herbal Drugs, vol. 49, no. 20, pp. 4773-4779, 2018.

[10] Q. K. Cui, Z. J. Wang, H. Y. Zhu et al., "Chemical constituent analysis of Xiao'er Zidian Zhenxiao granules based on UPLCQ-orbitrap-MS," China Journal of Traditional Chinese Medicine and Pharmacy, vol. 35, no. 5, pp. 2558-2562, 2020.

[11] L. Yang, S. Y. Liu, X. Zhou et al., "Rapid analysis on chemical constituents from Bushen Huoxue prescription by UPLC coupled with Q-exactive quadrupole-orbitrap MS," Chinese Journal of Pharmaceutical Analysis, vol. 39, no. 1, pp. 111-121, 2019.

[12] L. Zhou, Z. L. Li, C. Niu et al., "Analysis of chemical constituents of Fukejing capsules based on UPLC-Q-orbitrap HRMS," Chinese Journal of Hospital Pharmacy, vol. 38, no. 8, pp. 813-821, 2018.

[13] H. Y. Huang, J. L. Kang, Y. H. Yu et al., "Identification of chemical constituents of Bufei Yishen formula by UPLC-Qorbitrap MS," Journal of Instrumental Analysis, vol. 38, no. 1, pp. 1-13, 2019.

[14] J. H. Li, G. Kuang, X. H. Chen et al., "Identification of chemical composition of leaves and flowers from paeonia rockii by UHPLC-Q-exactive orbitrap HRMS," Molecules, vol. 21, no. 7, p. 947, 2019.

[15] W. X. Zhang, M. Feng, Y. L. Miao et al., "Analysis of chemical components of Huanbei Zhike Prescription based on UPLCQ-TOF-MS/MS technology," Zhongguo Zhong Yao Za Zhi, vol. 44, no. 14, pp. 3022-3034, 2019.

[16] J. Wang, Z. Jia, Z. Zhang et al., "Analysis of chemical constituents of Melastoma dodecandrum lour. by UPLC-ESI-Qexactive focus-MS/MS," Molecules, vol. 22, no. 3, p. 476, 2017.

[17] Y. Bai, Y. Zheng, W. Pang et al., "Identification and comparison of constituents of Aurantii fructus and Aurantii fructus immaturus by UFLC-DAD-triple TOF-MS/MS," Molecules, vol. 23, no. 4, p. 803, 2018. 
[18] D. Li, S.-H. Park, J.-H. Shim et al., "In vitro enzymatic modification of puerarin to puerarin glycosides by maltogenic amylase," Carbohydrate Research, vol. 339, no. 17, pp. 2789-2797, 2004.

[19] X. Shao, J. Zhao, X. Wang, and Y. Tao, "Rapid screening and quantitative determination of active components in QingHua-Yu-Re-formula using UHPLC-Q-TOF/MS and HPLCUV," Journal of Analytical Methods in Chemistry, vol. 2018, Article ID 8535127, 11 pages, 2018.

[20] Y. Mao, R. P. Zhang, J. H. He et al., "Determination of phenolic acids compounds in Arnebia euchroma(Royle) Johnstn. by Q exactive hybrid quadrupole-orbitrap mass spectrometer," Chinese Journal of Pharmaceutical Analysis, vol. 36, no. 7, pp. 1199-1206, 2016.

[21] M. Liu, P. Li, X. Zeng et al., "Identification and pharmacokinetics of multiple potential bioactive constituents after oral administration of radix astragali on cyclophosphamide-induced immunosuppression in Balb/c mice," International Journal of Molecular Sciences, vol. 16, no. 3, pp. 5047-5071, 2015.

[22] X. X. Qi, Y. Dong, C. X. Shan et al., "Analysis of the main components in herbal pair:astragali radix and salviae miltiorrhizae by UFLC-Q-TOF/MS," Journal of Nanjing University of Traditional Chinese Medicine, vol. 33, no. 1, pp. 93-96+103, 2017.

[23] Y. K. Yang, J. N. Du, J. Yao et al., "Fusion-fingerprint of Xueniao capsules based on HPLC and GC-MS," Chinese Journal of Pharmaceutical Analysis, vol. 38, no. 1, pp. 158-167, 2018.

[24] Y. Sun, F. Feng, T. H. Huang et al., "Rapid analysis of functional components of Hippophae rhamnoides by UPLCQ-exactive and OTCML database," Natural Product Research and Development, vol. 31, no. 7, pp. 1192-1202, 2019.

[25] X.-Q. Lei, G. Li, L. Cheng, X.-L. Wang, and F.-Y. Meng, "Identification of Ligustici rhizoma et radix and its adulterants based on their chemical constituents by UHPLC-Q/TOF-MS combined with data mining," Journal of Pharmaceutical and Biomedical Analysis, vol. 154, pp. 123-137, 2018.

[26] A. Ranasinghe, R. Ramanathan, M. Jemal, C. J. D’Arienzo, W. G. Humphreys, and T. V. Olah, "Integrated quantitative and qualitative workflow forin vivobioanalytical support in drug discovery using hybrid Q-TOF-MS," Bioanalysis, vol. 4, no. 5, pp. 511-528, 2012.

[27] Y. Zhang, W. T. Dong, J. H. Huo, and W. M. Wang, “Analysis on chemical constituents of Pheretima aspergillum by UPLCQ-TOF-MS," Chinese Traditional and Herbal Drugs, vol. 48, no. 2, pp. 252-262, 2017.

[28] Q. Q. Ren, Y. Q. Zhao, W. Xu et al., "Simultaneous determination of $5 \mathrm{~B}$-vitamins in compound trivitamin and calcium pantothenate syrup by UHILIC-MS/MS," Journal of Pharmaceutical Practice, vol. 36, no. 6, pp. 512-517, 2018.

[29] W. H. Qin, Y. Yang, Q. Li et al., "Analysis of chemical compositions from Nepal Cordyceps by UPLC-Q-TOF-MS," Chinese Journal of New Drugs, vol. 28, no. 13, pp. 1574-1581, 2019.

[30] M. Jiang, M. Zhou, Y. Han et al., "Identification of NF- $\kappa$ B Inhibitors in Xuebijing injection for sepsis treatment based on bioactivity-integrated UPLC-Q/TOF," Journal of Ethnopharmacology, vol. 147, no. 2, pp. 426-433, 2013.

[31] Y.-Y. Li, Y.-Y. Song, C.-H. Liu et al., "Simultaneous determination of esculin and its metabolite esculetin in rat plasma by LC-ESI-MS/MS and its application in pharmacokinetic study," Journal of Chromatography B, vol. 907, pp. 27-33, 2012.
[32] X. G. Wang, H. J. Yang, S. S. Wang et al., "Fragmentation pathways of five furocoumarine using line ion trap with orbitrapmass spectrometry," Zhongguo Zhong Yao Za Zhi, vol. 40, no. 7, pp. 1334-1341, 2015.

[33] J. Li, W. Z. M. Li, W. Huang et al., "Quality evaluation of Rhizoma belamcandae (Belamcanda chinensis (L.) DC.) by using high-performance liquid chromatography coupled with diode array detector and mass spectrometry," Journal of Chromatography A, vol. 1216, no. 11, pp. 2071-2078, 2009.

[34] H. J. Yu, H. Y. Li, Y. H. Yu, H. Li, and C. F. Wu, "The UPLCQ-TOF-MS analysis of wine lees," Food Research and Development, vol. 38, no. 3, pp. 162-165, 2017.

[35] Y. Tao, Y. H. Jaing, K. J. Tang, W. D. Li, and B. C. Cai, "Comparison of chemical constituents of crude and processed products of Rehmannia glutinosa by using UHPLC-Q-TOF/ MS," Traditional Chinese Drug Research and Clinical Pharmacology, vol. 27, no. 1, pp. 102-106, 2016.

[36] J. Zhang, X. J. Xu, W. Xu et al., "Rapid identification of chemical constituents from codonopsis radix by HPLC-LTQ-orbitrapMSn," Chinese Journal of Experimental Traditional Medical Formulae, vol. 21, no. 9, pp. 59-63, 2015.

[37] H. Liu, Y. F. Zheng, C. Y. Li et al., "Discovery of anti-inflammatory ingredients in Chinese herbal formula kouyanqing granule based on relevance analysis between chemical characters and biological effects," Scientific Reports, vol. 5, p. 18080, 2015.

[38] Y. Zhou, Y. Wang, R. Wang, F. Guo, and C. Yan, "Twodimensional liquid chromatography coupled with mass spectrometry for the analysis of Lobelia chinensis Lour. using an ESI/APCI multimode ion source," Journal of Separation Science, vol. 31, no. 13, pp. 2388-2394, 2008.

[39] F. Ferreres, C. Grosso, A. Gil-Izquierdo, P. Valentão, C. Azevedo, and P. B. Andrade, "HPLC-DAD-ESI/MSn analysis of phenolic compounds for quality control of Grindelia robusta Nutt. and bioactivities," Journal of Pharmaceutical and Biomedical Analysis, vol. 94, pp. 163-172, 2014.

[40] J. Gu, W. Wu, M. Huang, F. Long, X. Liu, and Y. Zhu, "Application of high-performance liquid chromatography coupled with linear ion trap quadrupole orbitrap mass spectrometry for qualitative and quantitative assessment of Shejin-Liyan granule supplements," Molecules, vol. 23, no. 4, p. 884, 2018.

[41] J. Xu, D. Qian, S. Jiang et al., "UPLC-Q-TOF/MS for analysis of the metabolites of flavone glycosides from Scutellaria baicalensis Georgi by human fecal flora in vitro," Chromatographia, vol. 76, no. 15-16, pp. 975-983, 2013.

[42] P. P. Wang, J. Luo, M. H. Yang, and L. Y. Kong, "Chemical constituents of Lobelia chinensis," Chinese Traditional and Herbal Drugs, vol. 44, no. 7, pp. 794-797, 2013.

[43] X. Feng, Y. Li, C. Guang et al., "Characterization of the in vivo and in vitro metabolites of linarin in rat biosamples and intestinal flora using ultra-high performance liquid chromatography coupled with quadrupole time-of-flight tandem mass spectrometry," Molecules, vol. 23, no. 9, p. 2140, 2018.

[44] G. Liu, J. Ma, Y. Chen et al., "Investigation of flavonoid profile of Scutellaria bacalensis Georgi by high performance liquid chromatography with diode array detection and electrospray ion trap mass spectrometry," Journal of Chromatography A, vol. 1216, no. 23, pp. 4809-4814, 2009.

[45] H. Pan, W. Pan, S. Zhao, Y. Du, Y. Li, and M. Yang, "UPLC fingerprint analysis and identification of flavonoids in Scutellaria indica by UFLC-triple-quadrupole time-of-flight mass 
spectrometry," Journal of Liquid Chromatography \& Related Technologies, vol. 40, no. 7, pp. 361-368, 2017.

[46] L. Gobbo-Neto, P. J. Gates, and N. P. Lopes, "Negative ion "chip-based" nanospray tandem mass spectrometry for the analysis of flavonoids in glandular trichomes of Lychnophora ericoides Mart. (Asteraceae)," Rapid Communications in Mass Spectrometry, vol. 22, no. 23, pp. 3802-3808, 2008.

[47] S.-J. Xu, L. Yang, X. Zeng, M. Zhang, and Z.-T. Wang, "Characterization of compounds in the Chinese herbal drug Mu-Dan-Pi by liquid chromatography coupled to electrospray ionization mass spectrometry," Rapid Communications in Mass Spectrometry, vol. 20, no. 22, pp. 3275-3288, 2006.

[48] F. G. Bueno, G. P. Panizzon, E. V. Mello et al., "Hydrolyzable tannins from hydroalcoholic extract from Poincianella pluviosa stem bark and its wound-healing properties: phytochemical investigations and influence on in vitro cell physiology of human keratinocytes and dermal fibroblasts," Fitoterapia, vol. 99, pp. 252-260, 2014.

[49] Q. C. Zang, J. J. He, J. F. Bai et al., "Rapid screening and quality evaluation for the harmful substance 5-hydroxymethyl furfural in commercially available traditional Chinese medicine injection using LC-MS/MS method," Yao Xue Xue Bao, vol. 48, no. 11, pp. 1705-1709, 2034. 